\title{
Static and seismic passive earth pressure coefficients on rigid retaining structures
}

\author{
A.-H. Soubra
}

\begin{abstract}
The passive earth pressure problem is investigated by means of the kinematical method of the limit analysis theory. A translational kinematically admissible failure mechanism composed of a sequence of rigid triangles is proposed. This mechanism allows the calculation of the passive earth pressure coefficients in both the static and seismic cases. Quasi-static representation of earthquake effects using the seismic coefficient concept is adopted. Rigorous upper-bound solutions are obtained in the framework of the limit analysis theory. The numerical results of the static and seismic passive earth pressure coefficients are presented and compared with the results of other authors.
\end{abstract}

Key words: limit analysis, passive pressure, earthquake.

Résumé : La méthode cinématique de la théorie de l'analyse limite a été appliquée à l'étude de la butée des terres. Un mécanisme de rupture cinématiquement admissible de type translationnel est proposé. Ce mécanisme est composé de plusieurs blocs triangulaires rigides et il permet le calcul des coefficients de butée avec une prise en compte éventuelle des efforts sismiques grâce à une approche pseudo-statique. La solution présente est un majorant par rapport à la solution théorique exacte. Les résultats numériques obtenus sont présentés et comparés à ceux donnés par d'autres auteurs.

Mots clés : analyse limite, butée des terres, séisme.

\section{Introduction}

Earthquakes have the unfavorable effects of increasing active lateral earth pressures and reducing passive lateral earth pressures. Hence, the assessment of seismic lateral earth pressures or changes in lateral earth pressures as the result of an earthquake is of practical significance in most seismic designs of retaining walls. The traditional method for evaluating the effect of an earthquake on the lateral earth pressures is the so-called "pseudo-static method." This method continues to be used by consulting geotechnical engineers because it is required by the building codes; it is easy to apply and gives satisfactory results. Quasi-static analysis using the seismic coefficient concept is therefore of great practical value in many cases, although the assessment of the seismic coefficient still relies highly on past experience.

The well-known Mononobe-Okabe analysis of seismic lateral earth pressures proposed by Mononobe and Matsuo (1929) and Okabe (1924) is a direct modification of the Coulomb wedge method where the earthquake effects are replaced by a quasi-static inertia force whose magnitude is computed on the basis of the seismic coefficient concept. As in the Coulomb analysis, the failure surface is assumed to be planar in the Mononobe-Okabe method, regardless of the

A.-H. Soubra. École Nationale Supérieure des Arts et Industries de Strasbourg, 24, Boulevard de la Victoire, 67084 Strasbourg CEDEX, France. fact that the most critical sliding surface may be curved. Similar to the Coulomb analysis, the Mononobe-Okabe analysis may underestimate the active earth pressure and overestimate the passive earth pressure. Note, however, that the Mononobe-Okabe analysis has been experimentally proved by Mononobe and Matsuo (1929) and Ishii et al. (1960) to be effective in assessing the seismic active earth pressure; it is generally adopted in current practice for seismic design of rigid retaining walls. The Mononobe-Okabe solution is therefore practically acceptable at least for the active pressure case, although its applicability to the passive pressure case is somewhat in doubt.

Recent research conducted by Chang and Chen (1982) (cf. Chen and Liu 1990) using a log-sandwich mechanism within the framework of the kinematical method in limit analysis has shown that the upper-bound solutions they obtained were practically identical to those given by the MononobeOkabe method for the active case. However, the passive earth pressure coefficients are seriously overestimated by the Mononobe-Okabe method; they are in most cases higher than those obtained by the upper-bound method for a logsandwich mechanism.

In this paper, the static and seismic passive earth pressure problems are investigated by the upper-bound method of limit analysis using a translational failure mechanism. This mechanism allows the slip surface to develop more freely in comparison with the log-sandwich mechanism presented by Chen and Rosenfarb (1973) (cf. Chen 1975 and Chen and Liu 1990) in the static case and by Chang and Chen (1982) 
(cf. Chen and Liu 1990) in the seismic case; hence it leads to smaller upper-bound solutions of the passive earth pressure problem.

\section{The upper- and lower-bound theorems of limit analysis}

The upper-bound theorem, which assumes a perfectly plastic soil model with an associated flow rule, states that the rate of energy dissipation in any kinematically admissible velocity field can be equated to the rate of work done by the external forces, and so enables a strict upper-bound on the true limit load to be deduced (see Drucker et al. 1952; Chen 1975; and Salençon 1990). A kinematically admissible velocity field is one which satisfies compatibility, the flow rule, and the velocity boundary conditions. To provide solutions that are useful in practice, the upper-bound theorem is often used in tandem with the lower-bound theorem. The latter also assumes a perfectly plastic soil model with an associated flow rule and states that any statically admissible stress field (which satisfies equilibrium and the stress boundary conditions, and nowhere violates the yield criterion) will provide a lower-bound estimate of the true limit load (see Drucker et al. 1952; Chen 1975; Salençon 1990). By using these two theorems, the exact limit load can often be bracketed with an accuracy which is sufficient for design purposes.

In this paper, only the upper-bound theorem of limit analysis is applied to the static and seismic passive earth pressure problem using a kinematically admissible velocity field. It should be noted here that the upper-bound theorem gives an unsafe estimate of the passive failure load. The aim of this work is to improve the best available upper-bound solutions given by Chen and Liu (1990) in both the static and seismic cases.

\section{Theoretical analysis of the seismic passive earth pressure problem}

An earthquake has two possible effects on a soil-wall system. One is to increase the driving forces, and the other is to decrease the shearing resistance of the soil. The reduction in the shearing resistance of a soil during an earthquake is in effect only when the magnitude of the earthquake exceeds a certain limit and the ground conditions are favorable for such a reduction. Research conducted by Okamoto (1956) indicated that when the average ground acceleration is larger than $0.3 g$, there is considerable reduction in strength for most soils. However, he claimed that in many cases the ground acceleration is less than $0.3 g$, and the mechanical properties of most soils do not change significantly in these cases.

The assumptions made in the analysis can be summarized as follows:

(1) Only the reduction of the passive pressures due to the increase in driving forces is investigated under seismic loading conditions. The shear strength of the soil is assumed unaffected as the result of the seismic loading. This hypothesis is currently made by consulting geotechnical engineers (see, for instance, Commission of the European Communities 1994) and it has been adopted by many investigators in the seismic stability analysis of geotechnical problems (see, for instance, Sarma and Iossifelis 1990; Richards et al. 1993; Budhu and Al-Karni 1993; Paolucci and Pecker 1997; and Soubra 1997, 1999).

(2) A constant seismic coefficient is assumed for the entire soil mass involved. Only the horizontal seismic coefficient $K_{\mathrm{h}}$ is considered, the vertical seismic coefficient often being disregarded.

(3) A translational multiblock failure mechanism is assumed. This mechanism is a generalization of the one-block failure mechanism considered in the Mononobe-Okabe method.

(4) The soil is assumed to be an associated flow rule Coulomb material obeying the maximal work principle of Hill. However, real soils do not obey the associative flow rule, since frictional soils are found experimentally to dilate at increments considerably less than those predicted by the normality condition, that is, dilatancy angle $(\psi)<$ angle of internal friction $(\phi)$. Recent theoretical considerations made on translational failure mechanisms (Drescher and Detournay 1993; Michalowski and Shi 1995, 1996) allow one to conclude that for a nonassociative material the limit load can be obtained using the flow rule associated with a new yield condition in which $\phi$ and cohesion $c$ are replaced by $\phi^{*}$ and $c^{*}$ as follows:

$$
\begin{aligned}
& \tan \phi^{*}=\frac{\cos \Psi \sin \phi}{1-\sin \Psi \sin \phi} \\
& c^{*}=\frac{\cos \Psi \cos \phi}{1-\sin \Psi \sin \phi} c
\end{aligned}
$$

Hence, the results presented in this paper can be used for nonassociative material provided $\phi$ and $c$ are replaced with $\phi^{*}$ and $c^{*}$ calculated from eqs. [1] and [2], respectively.

(5) The angle of friction $\delta$ at the soil-structure interface is assumed to be constant. This hypothesis is in conformity with the kinematics assumed in this paper.

(6) An adhesive force $P_{\mathrm{a}}$ is assumed to act at the soilstructure interface. The intensity of this force is $c l(\tan \delta) /(\tan \phi)$, where $l$ is the length of the structure.

(7) The velocity at the soil-structure interface is assumed tangential to the wall (see Chen 1975). Other investigators (see Drescher and Detournay 1993; and Michalowski 1999) assumed that the interfacial velocity is inclined at $\delta$ to the wall to respect the normality condition. Both hypotheses lead to the same result of the limit load (see Appendix 1).

\subsection{Failure mechanism}

The failure mechanism is shown in Fig. 1. It is composed of a radial shear zone including $n$ triangular rigid blocks. The angles $\alpha_{i}$ and $\beta_{i}(i=1, \ldots, n)$ are as yet unspecified.

As shown in Fig. $2 a$, the wall is translating horizontally and all the triangles move as rigid bodies in directions which make an angle $\phi$ with the discontinuity lines $d_{i}(i=1, \ldots, n)$.

The velocity of each triangle is determined by the condition that the relative velocity between the triangles in contact should have a direction which forms an angle $\phi$ with the contact surface. The velocity hodographs are shown in Fig. $2 b$. The velocities so determined constitute a kinematically admissible velocity field. 
Fig. 1. Failure mechanism for static and seismic passive earth pressure analyses.

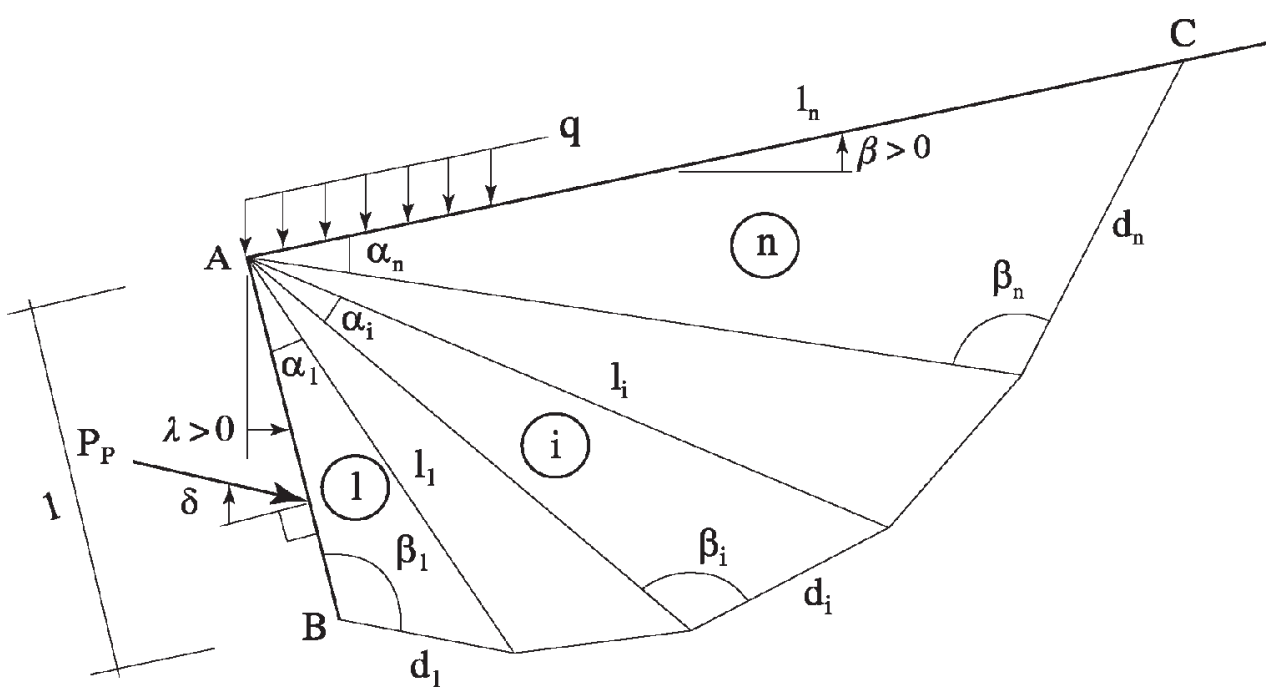

Fig. 2. (a) Velocity field of the failure mechanism. (b) Velocity hodographs.

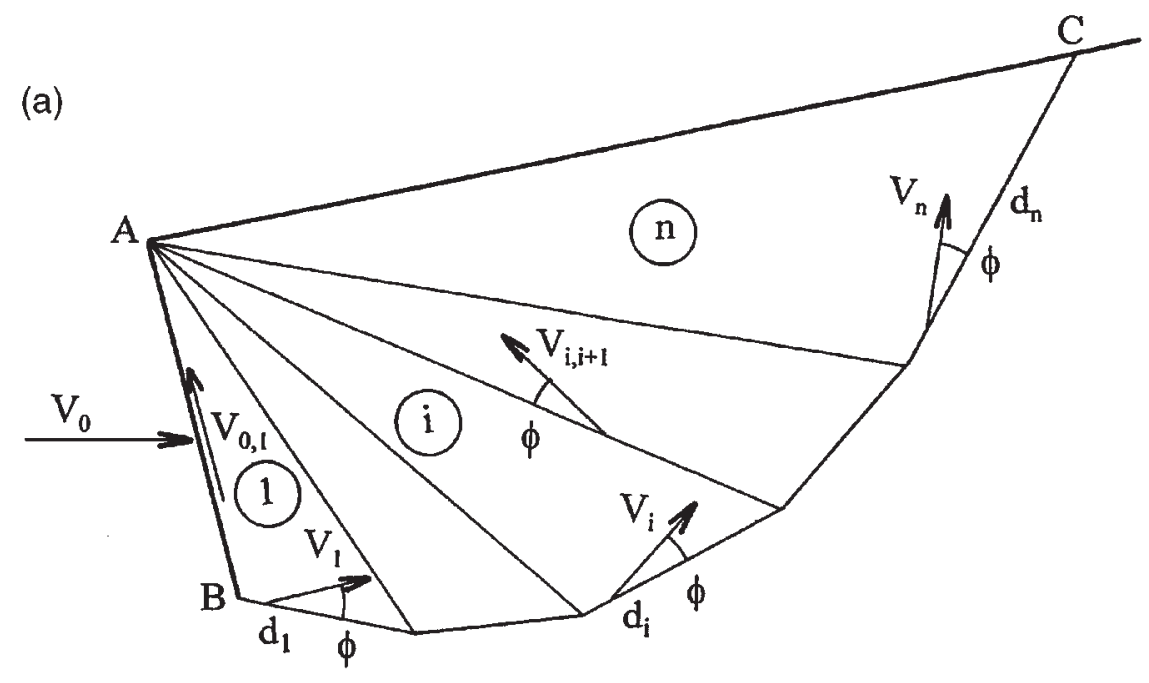

(b)

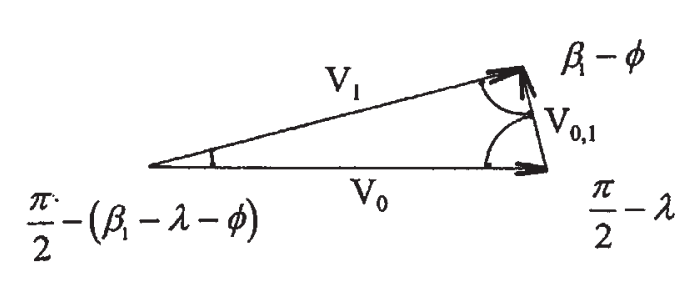

$$
\beta_{i+1}-2 \phi
$$

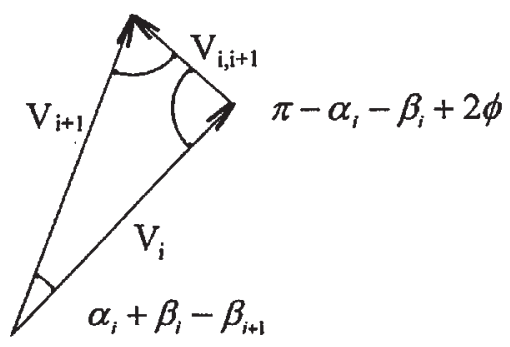

In the present analysis, the work equation is applied to the soil mass in motion. Two another alternative approaches considering the whole soil-structure system can also be used and lead to an identical limit load (see Appendix 1).

\subsubsection{Calculations of rate of external work}

As shown in Fig. 3, the external forces contributing to the rate of external work consist of the passive earth force $P_{\mathrm{pE}}$, the adhesive force $P_{\mathrm{a}}$, the weight of the soil mass $W_{i}(i=$
$1, \ldots, n)$ the surcharge $q$ on the ground surface, and the different inertia forces. These inertia forces concern the soil mass and the surcharge loading.

The rate of external work for the different external forces can be easily obtained; the calculations are presented in Appendix 2.

\subsubsection{Calculations of rate of internal energy dissipation}

Since no general plastic deformation of the soil mass is permitted to occur, the energy is dissipated solely at the dis- 
Fig. 3. Free body diagram of the failure mechanism.

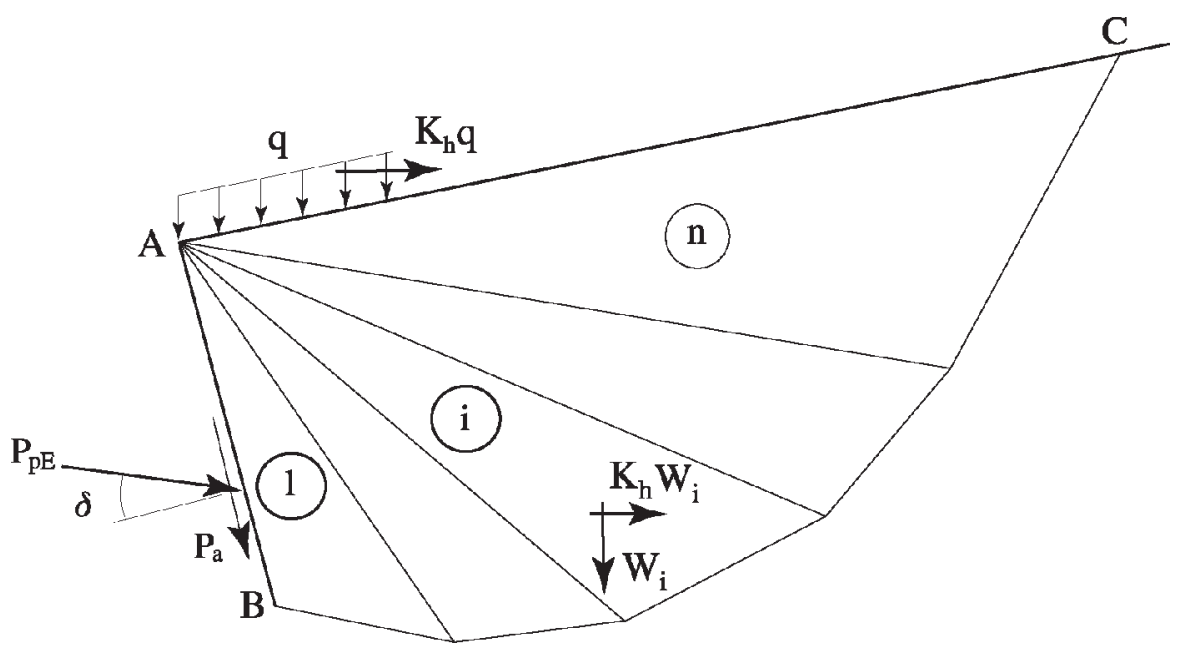

continuity surfaces $d_{i}(i=1, \ldots, n)$ between the material at rest and the material in motion and at the discontinuity surfaces $l_{i}(i=1, \ldots, n-1)$ within the radial shear zone. The rate of energy dissipation per unit length along such velocity discontinuities can be expressed as

[3] $\dot{D}=c V \cos \phi$

where $V$ is the velocity that makes an angle $\phi$ with the velocity discontinuity according to the associated flow rule of perfect plasticity. Calculations of the rate of energy dissipation along the different velocity discontinuities are given in Appendix 2 .

\subsubsection{Work equation}

By equating the total rate of external work (eq. [B14], Appendix 2) to the total rate of internal energy dissipation (eq. [B19], Appendix 2), we have

$$
\begin{aligned}
& P_{\mathrm{pE}}= \\
& \quad K_{\mathrm{p} \gamma \mathrm{E}}\left(\alpha_{i}, \beta_{i}\right) \frac{\gamma l^{2}}{2}+K_{\mathrm{pqE}}\left(\alpha_{i}, \beta_{i}\right) q l+K_{\mathrm{pcE}}\left(\alpha_{i}, \beta_{i}\right) c l
\end{aligned}
$$

in which the seismic passive earth pressure coefficients $K_{\mathrm{p} \gamma \mathrm{E}}$, $K_{\mathrm{pqE}}$, and $K_{\mathrm{pcE}}$ can be expressed in terms of the $2 n-1$ as yet unspecified angles $\alpha_{i}$ and $\beta_{i}$. They are given as follows:

$$
\begin{aligned}
& K_{\mathrm{p} \gamma \mathrm{E}}=-\frac{f_{1}+K_{\mathrm{h}} f_{2}}{\sin \left(\beta_{1}-\phi-\delta\right)} \\
& K_{\mathrm{pqE}}=-\frac{f_{3}+K_{\mathrm{h}} f_{4}}{\sin \left(\beta_{1}-\phi-\delta\right)} \\
& K_{\mathrm{pcE}}=\frac{f_{5}+f_{6}+f_{7}}{\sin \left(\beta_{1}-\phi-\delta\right)}
\end{aligned}
$$

\section{Numerical results}

The most critical passive earth pressure coefficients can be obtained by minimization of these coefficients (eqs. [5]-[7]) with regard to the mechanism parameters. A computer program has been developed for assessing the critical static and seismic passive earth pressure coefficients. In the following
Table 1. $K_{\mathrm{p} \gamma}$ values versus number of rigid blocks $n$ for $\phi=45^{\circ}, \delta / \phi=1, \beta / \phi=1$, and $\lambda / \phi=0$.

\begin{tabular}{rrr}
\hline$n$ & $K_{\mathrm{p} \gamma}$ & $\%$ reduction \\
\hline 2 & 2362.66 & \\
3 & 673.26 & 71.50 \\
4 & 499.92 & 25.75 \\
5 & 441.87 & 11.61 \\
6 & 414.50 & 6.19 \\
7 & 399.18 & 3.70 \\
8 & 389.68 & 2.38 \\
9 & 383.34 & 1.63 \\
10 & 378.90 & 1.16 \\
11 & 375.65 & 0.86 \\
12 & 373.21 & 0.65 \\
13 & 371.32 & 0.51 \\
14 & 369.83 & 0.40 \\
\hline
\end{tabular}

sections, we present and discuss in succession $(i)$ the static passive earth pressure coefficients $K_{\mathrm{p} \gamma}, K_{\mathrm{pq}}$, and $K_{\mathrm{pc}}$ given by the present failure mechanism for $K_{\mathrm{h}}=0$; and (ii) the seismic passive earth pressure coefficients $K_{\mathrm{p} \gamma \mathrm{E}}, K_{\mathrm{pqE}}$, and $K_{\mathrm{pcE}}$ for various values of the seismic coefficient $K_{\mathrm{h}}$.

\subsection{Static passive earth pressure coefficients}

Table 1 presents the $K_{\mathrm{p} \gamma}$ factor obtained from the computer program for $\phi=45^{\circ}, \delta / \phi=1, \beta / \phi=1, \lambda / \phi=0, K_{\mathrm{h}}=0$, and various values of $n$ (the number of triangular rigid blocks).

The upper-bound solution can be improved by increasing the number of rigid blocks. The reduction in the $K_{\mathrm{p} \gamma}$ value decreases with an increase in $n$ and attains $0.4 \%$ for $n=14$. The same trend has been observed for the coefficients $K_{\mathrm{pq}}$ and $K_{\mathrm{pc}}$.

On the other hand, the results obtained from the computer program indicate that the coefficient $K_{\mathrm{pc}}$ is related to the coefficient $K_{\mathrm{pq} 0}$ by the following relationship (cf. theorem of corresponding states of Caquot and Kérisel 1948):

$$
K_{\mathrm{pc}}=\frac{K_{\mathrm{pq} 0}-\frac{1}{\cos \delta}}{\tan \phi}
$$


Fig. 4. Critical slip surfaces for $\phi=45^{\circ}, \delta / \phi=2 / 3, \beta / \phi=1 / 3$, $\lambda / \phi=0$, and three values of $n(3,7$, and 14$)$.
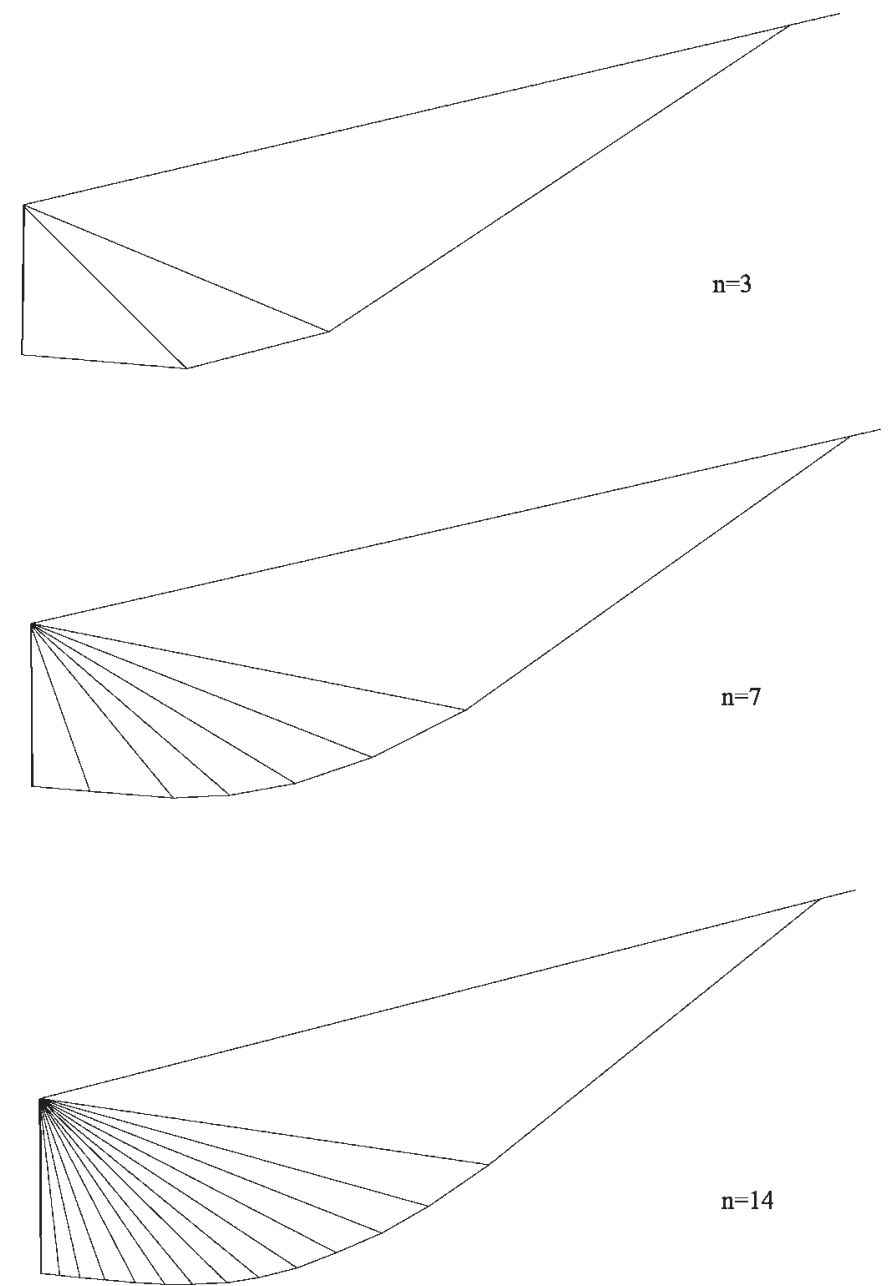

where $K_{\mathrm{pq} 0}$ is the coefficient of passive earth pressures due to a surcharge loading acting normally to the ground surface. This result is to be expected, since in the present analysis an adhesive force $P_{\mathrm{a}}=c l(\tan \delta) /(\tan \phi)$ is assumed to act along the soil-wall interface.

Figure 4 shows the critical slip surfaces obtained from the numerical minimization of the coefficient $K_{\mathrm{p} \gamma}$ for $\phi=45^{\circ}$, $\delta / \phi=2 / 3, \beta / \phi=1 / 3, \lambda / \phi=0$, and three values of $n(3,7$, and 14).

For $n=14$, the critical failure mechanism is composed of a radial shear zone sandwiched between two triangular rigid wedges. The shear zone is not bounded by a log-spiral slip surface as is the case of the log-sandwich mechanism proposed by Chen and Rosenfarb (1973). Thus, the present mechanism leads to smaller upper-bound solutions of the passive earth pressure coefficient $K_{\mathrm{p} \gamma}$. However, the coefficients $K_{\mathrm{pq}}$ and $K_{\mathrm{pc}}$ are identical to those given by the logsandwich mechanism, since the multiblock mechanism approaches the log-sandwich mechanism as the number of rigid blocks increases. The coefficients $K_{\mathrm{pq}}$ and $K_{\mathrm{pc}}$ are also almost identical to those given by L'herminier and Absi (1962) (cf. Kérisel and Absi 1990) using the slip line method, and the maximum error does not exceed $0.5 \%$. It should be noted that the critical angular parameters $\left(\alpha_{i}, \beta_{i}\right)$ obtained from the minimization of both $K_{\mathrm{pq}}$ and $K_{\mathrm{pc}}$ give exactly the same critical geometry.

Table 2 presents the coefficients $K_{\mathrm{p} \gamma}$ and $K_{\mathrm{pq}}$ obtained from the computer program for $\phi$ ranging from $10^{\circ}$ to $45^{\circ}$ and five values of $\delta / \phi$ when $\beta / \phi=\lambda / \phi=0$; the coefficient $K_{\mathrm{pc}}$ can be calculated using eq. [8]. In Table 2 and hereafter, the results are given for $n=14$, which means that the minimization procedure is made with regard to 27 angular parameters.

\subsubsection{Comparison with Rankine's solution}

For the general case of an inclined wall with a sloped backfill $(\beta / \phi \neq 0, \lambda / \phi \neq 0)$, the Rankine passive earth pressure coefficient $K_{\mathrm{p} \gamma}$ is given as follows (cf. Costet and Sanglerat 1975):

$$
K_{\mathrm{p} \gamma}=\frac{\cos (\lambda-\beta) \sin \omega_{\beta}}{\cos \alpha \sin \left(\omega_{\beta}-\beta\right)}\left[1+\sin \phi \cos \left(\omega_{\beta}+\beta-2 \lambda\right)\right]
$$

where

[10] $\quad \sin \omega_{\beta}=\frac{\sin \beta}{\sin \phi}$

As is well known, this pressure is inclined at an angle $\alpha$ with the normal to the wall (cf. Fig. 5) irrespective of the angle of friction at the soil-wall interface, where

$$
\tan \alpha=\frac{\sin \left(\omega_{\beta}+\beta-2 \lambda\right) \sin \phi}{1+\sin \phi \cos \left(\omega_{\beta}+\beta-2 \lambda\right)}
$$

and the inclination of the slip surface with the horizontal direction is given as follows:

$$
\theta=\frac{\omega_{\beta}+\beta}{2}+\frac{\pi}{4}-\frac{\phi}{2}
$$

To validate the results of the present analysis, one considers a soil-wall friction angle $\delta$ equal to the $\alpha$ value given by Rankine. The numerical solutions obtained from the computer program have shown that in this special case the present results are similar to the exact solutions given by Rankine (eqs. [9] and [12]).

\subsubsection{Comparison with Caquot and Kérisel (1948) and Chen and Rosenfarb (1973)}

As mentioned earlier, the log-sandwich mechanism proposed by Chen and Rosenfarb (1973) gives the exact solution solely in the case of a weightless soil. As a result, the comparison of the present solutions with solutions of other authors will be limited to the passive earth pressure coefficient $K_{\mathrm{p} \gamma}$.

There are many solutions for $K_{\mathrm{p} \gamma}$ in the literature based on (i) the limit equilibrium method (Janbu 1957; Rowe 1963; Lee and Moore 1968; Packshaw 1969; Shields and Tolunay 1972, 1973; Spencer 1975; Rahardjo and Fredlund 1984; Bilz et al. 1985), (ii) the slip line method (Caquot and Kérisel 1948; Sokolovski 1960, 1965; Graham 1971; Hettiaratchi and Reece 1975); and (iii) the limit analysis theory (Lysmer 1970; Lee and Herington 1972; Chen and Rosenfarb 1973; Basudhar et al. 1979; Soubra 1989, Soubra et al. 1998, 1999; Chen and Liu 1990). The tendency today 
Table 2. $K_{\mathrm{p} \gamma}$ and $K_{\mathrm{pq}}$ values for $\phi$ ranging from $10^{\circ}$ to $45^{\circ}$ and $\delta / \phi$ of $0,1 / 3,1 / 2,2 / 3$, and $1(\beta / \phi=\lambda / \phi=0)$.

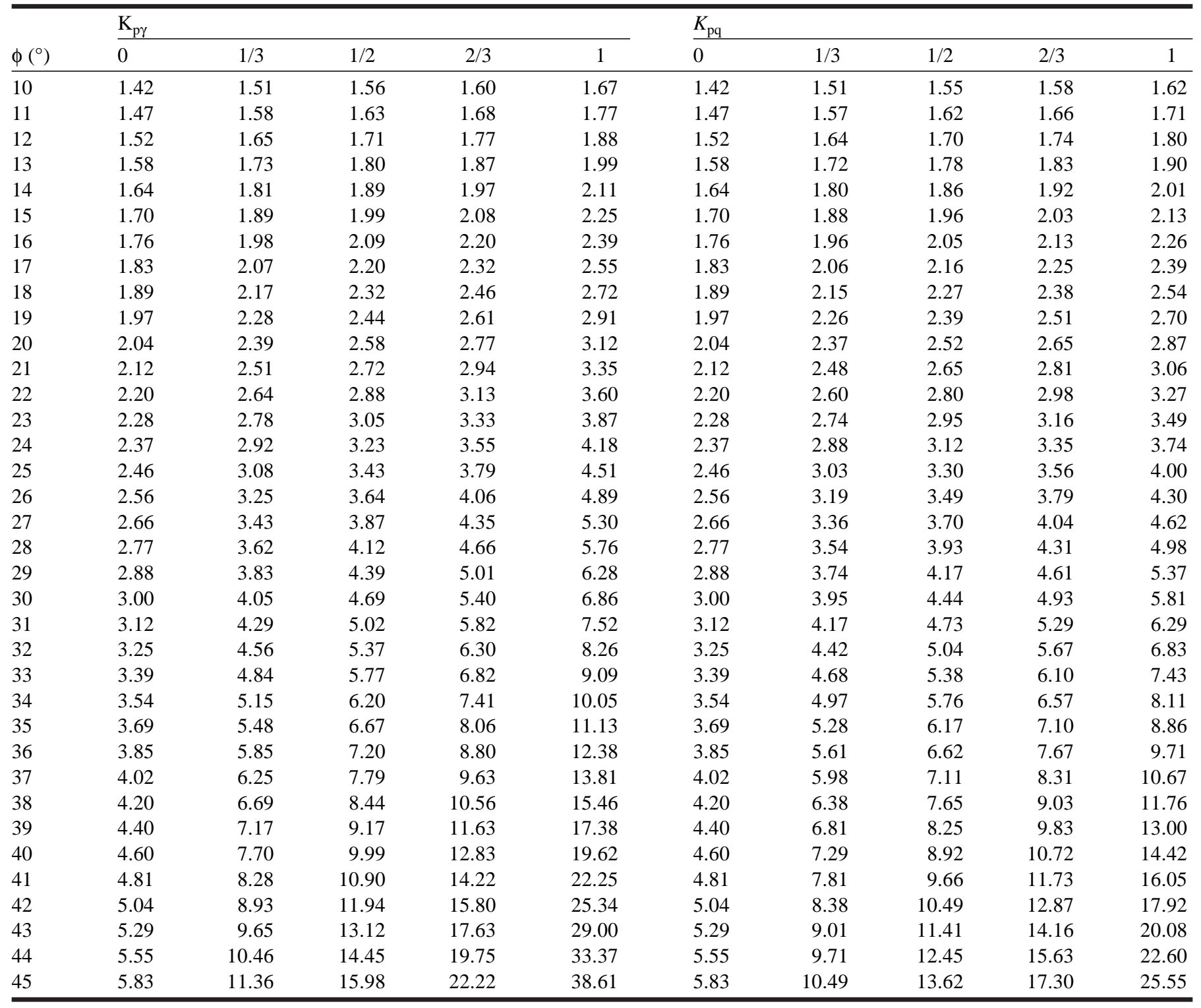

in practice is to use the values given by Caquot and Kérisel (1948) (cf. Tables of Kérisel and Absi 1990).

Figure 6 shows the comparison of the present solutions with those of Caquot and Kérisel (1948) (cf. Kérisel and Absi 1990) in the case of a vertical wall and horizontal backfill $(\beta / \phi=\lambda / \phi=0)$.

The values from the present analysis are greater than those of Caquot and Kérisel, with the maximum difference being less than $12 \%$.

Figure 7 shows the comparison of the present solutions with those of Caquot and Kérisel (1948) for different values of $\beta$ and $\lambda$ when $\phi=45^{\circ}$ and $\delta / \phi=1$.

As in the case of a vertical wall and a horizontal backfill, the values from the present analysis are greater than those of Caquot and Kérisel (1948). The difference is not significant for small values of $\beta / \phi(\leq-0.4)$ and for large values of $\lambda\left(\geq 25^{\circ}\right)$; however, it attains $38 \%$ when $\phi=45^{\circ}, \delta / \phi=1$, $\beta / \phi=1$, and $\lambda / \phi=-1 / 3$. Note that for practical configu-
Fig. 5. Rankine solution in the case of a general soil-wall system.

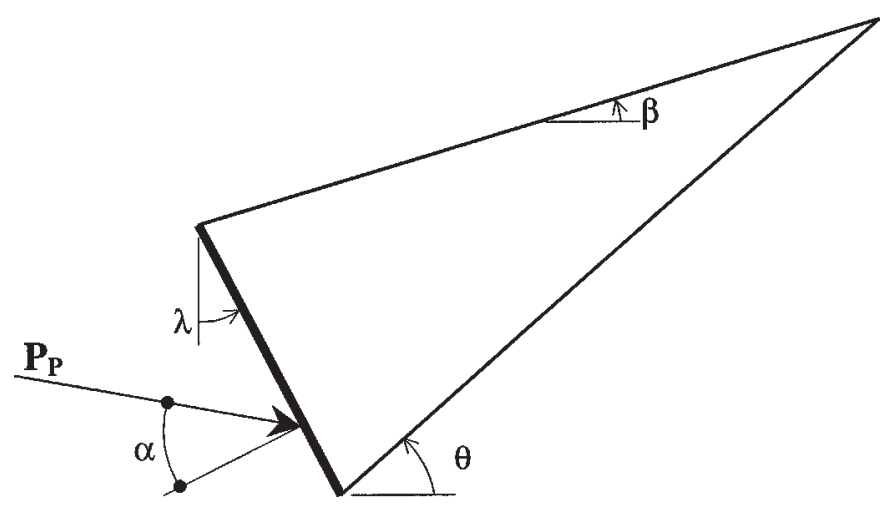

rations $\left(\phi \leq 45^{\circ}, 0 \leq \delta / \phi \leq 2 / 3, \lambda / \phi=0, \beta / \phi \leq 1 / 3\right)$ the maximum difference does not exceed $12.2 \%$. 
Fig. 6. Comparison of the coefficient $K_{\mathrm{p} \gamma}$ from the present solution with that of Caquot and Kérisel (1948) $(\beta / \phi=\lambda / \phi=0)$.

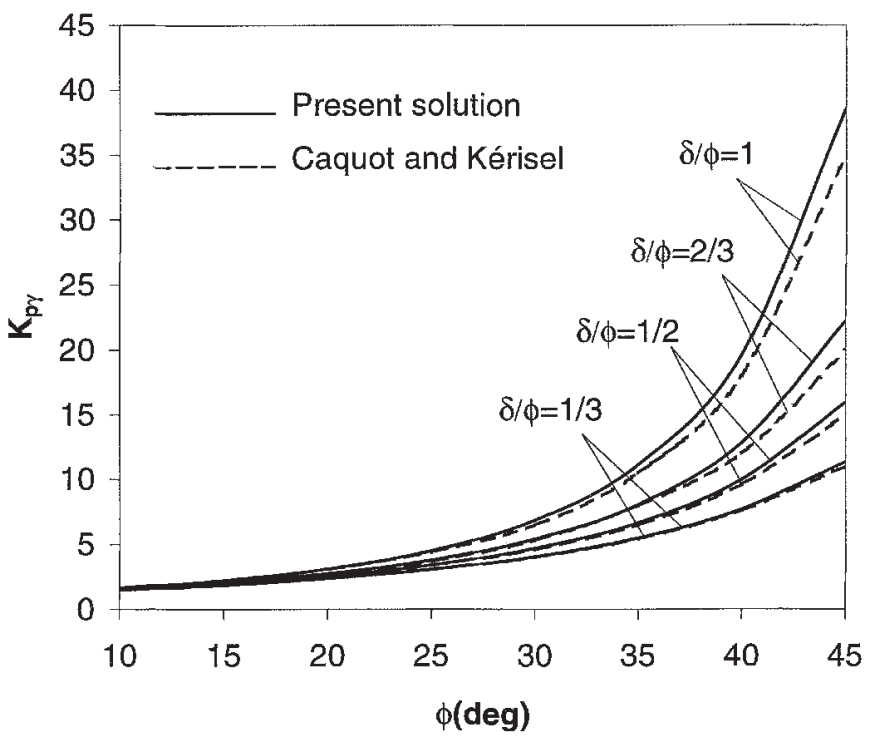

On the other hand, rigorous upper-bound solutions are proposed in the literature by Chen and Rosenfarb (1973). These authors considered six failure mechanisms and showed that the log-sandwich mechanism gives in most cases the least upper-bound solutions. The results given by the present failure mechanism and those given by the logsandwich mechanism proposed by Chen and Rosenfarb are presented in Fig. 8 in the case of $\phi=45^{\circ}$ and $\delta / \phi=1$.

It is clear that the present upper-bound solutions are better than those of Chen and Rosenfarb (1973); the improvement attains $21 \%$ when $\phi=45^{\circ}, \delta / \phi=1, \beta / \phi=1$, and $\lambda / \phi=-1 / 3$.

\subsubsection{Comparison with other theoretical and experimental solutions}

Recently, Kobayashi (1998) performed laboratory tests to compare the experimental passive earth pressure coefficients obtained in the case of a large wall oblique angle with those given by theoretical predictions based on the rigid plasticity theory. The passive wall was pushed into a sand mass using two different methods. Method A translates the passive wall normally with a slight shear force, whereas method B sinks the passive wall vertically with a full shear force. The relationship between the observed $K_{\mathrm{p} \gamma}$ and $\tan \delta$ is demonstrated in Fig. 9. Passive earth pressure coefficients given by the present analysis, by Chen and Rosenfarb (1973) (cf. Chen 1975) using the upper-bound method in limit analysis, and by Sokolovski (1960) using the slip line method are also indicated in Fig. 9.

Observed values of $K_{\mathrm{p} \gamma}$ are smaller than the theoretical predictions for large values of $\delta$ and $K_{\mathrm{p} \gamma}$ decreases considerably from the peak to the residual. This may be explained by the progressive failure observed along a shear band. On the other hand, the comparison with the theoretical results given by Chen (1975) indicates that our solution improves the best upper-bound solution given by this author. The improvement attains $20.4 \%$ when $\phi=42^{\circ}, \tan \delta=0.9, \lambda=-60^{\circ}$, and $\beta=$ $0^{\circ}$. The present solutions are greater than those given by Sokolovski (1960), and the difference attains $19 \%$ when $\phi=$ $42^{\circ}, \tan \delta=0.9, \lambda=-60^{\circ}$, and $\beta=0^{\circ}$.
Fig. 7. Comparison of the coefficient $K_{\mathrm{p} \gamma}$ from the present solution with that of Caquot and Kérisel (1948) for different $\beta$ and $\lambda$ values.

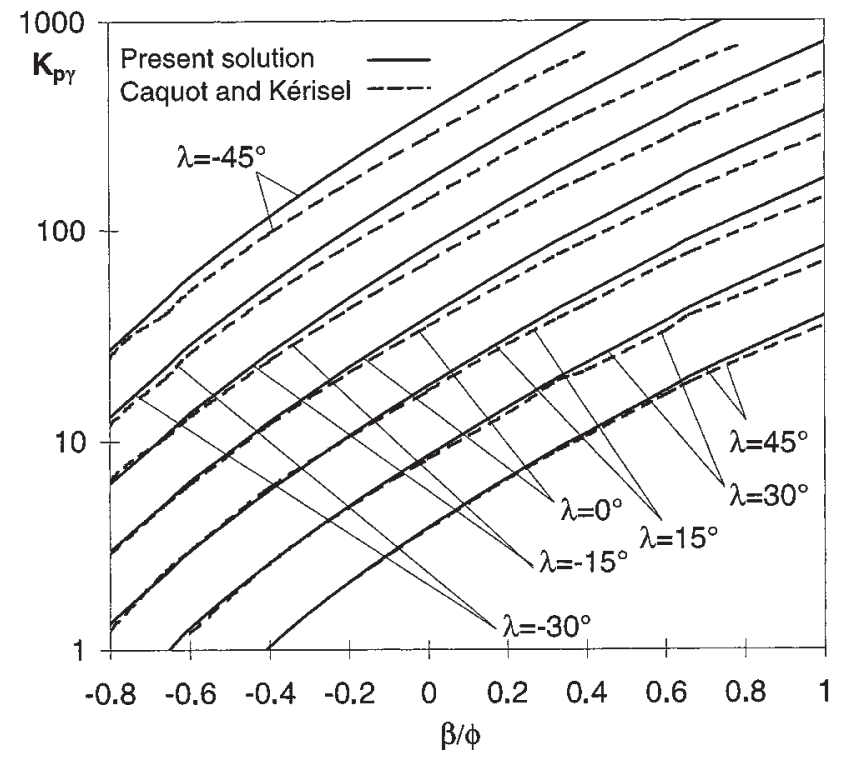

Fig. 8. Comparison of the coefficient $K_{\mathrm{p} \gamma}$ from the present solution with that of Chen and Rosenfarb (1973) for different $\beta$ and $\lambda$ values.

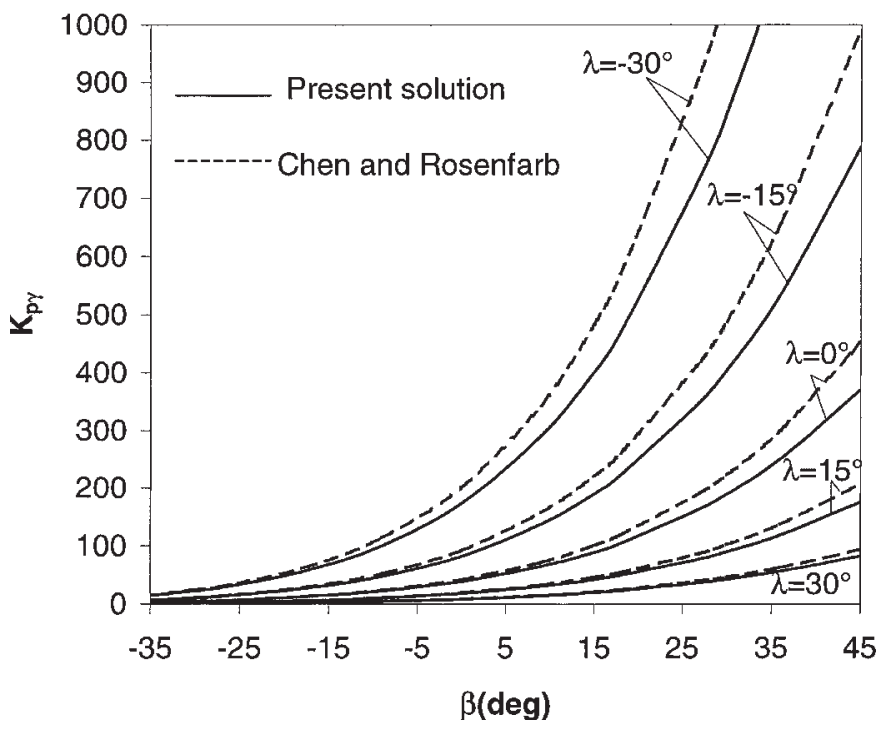

Fang et al. (1997) presented experimental data of earth pressure acting against a vertical rigid wall which moves toward a mass of dry sand with an inclined surface. The instrumented retaining-wall facility was used to investigate the variation of earth pressure induced by the translational wall movement. Based on experimental data, it has been found that the earth pressure distributions are essentially linear at each stage of wall movement and that the wall movement $S / H$ (where $S$ is the horizontal wall movement and $H$ is the wall height) required for the backfill to reach a passive state increases with an increasing backfill inclination $\beta$. 
Fig. 9. Comparison of results from the present solution with other theoretical and experimental results (Chen 1975; Sokolovski 1960; Kobayashi 1998 "Methods A and B").
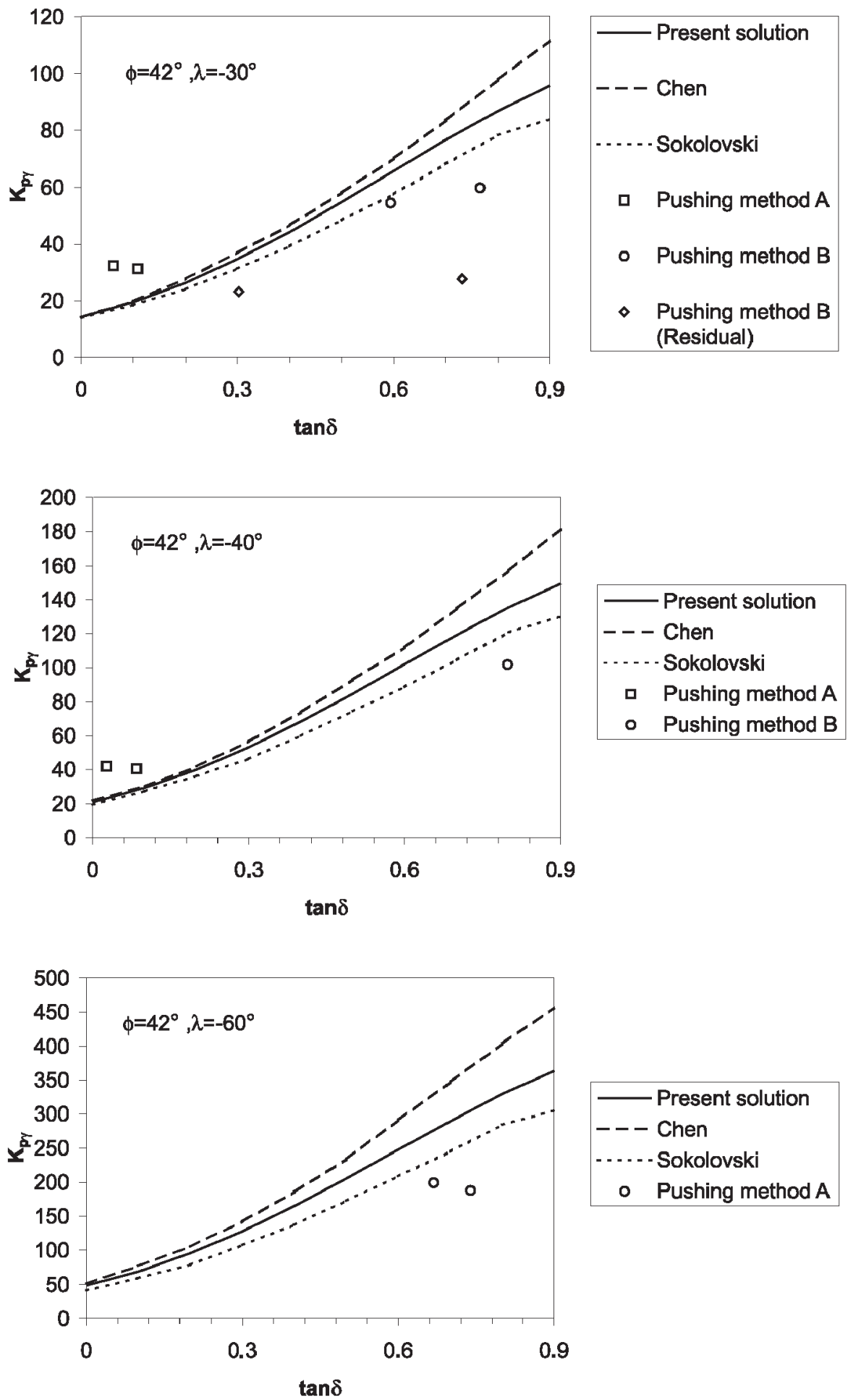

The relationship between the passive earth pressure coefficient $K_{\mathrm{p} \gamma \mathrm{h}}$ and backfill inclination $\beta$ at a different stage of wall movement $S / H$ is demonstrated in Fig. 10.

Figure 10 shows that $K_{\mathrm{p} \gamma, \mathrm{h}}$ increases with increasing sloping angle $\beta$. For large values of $\beta$, the experimental $K_{\mathrm{p} \gamma, \mathrm{h}}$ values occur at a large wall displacement. As an example, for $\beta=20^{\circ}$, the required wall movement is $0.46 \mathrm{H}$. For an arbitrarily assumed displacement criterion $(S / H=0.2)$ chosen by the authors, the present results and those given by the log-spiral method proposed by Terzaghi (1943) are in fairly good agreement with the experimental data.

\subsection{Seismic passive earth pressure coefficients}

Earthquakes have the unfavorable effect of reducing passive earth pressures. Equation [7] shows that the coefficient $K_{\text {pcE }}$ is unaffected by the seismic loading. To investigate how 
Fig. 10. Comparison of results from the present solution with other theoretical and experimental results (Terzaghi 1943 ; Fang et al. 1997) $\left(\phi=30.9^{\circ}, \delta=19.2^{\circ}\right.$, and $\left.\lambda=0^{\circ}\right)$.
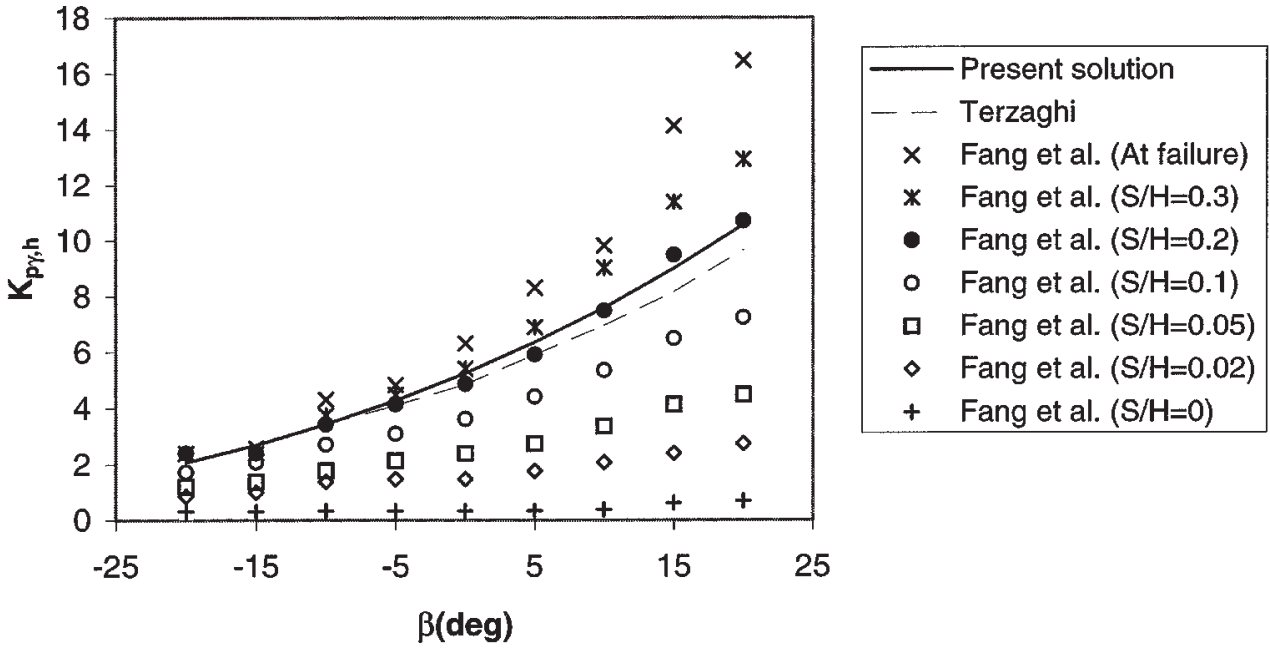

Table 3. Seismic passive earth pressure coefficient $K_{\mathrm{p} \gamma \mathrm{E}}(\beta / \phi=\lambda / \phi=0)$.

\begin{tabular}{|c|c|c|c|c|c|c|c|c|}
\hline \multirow[b]{2}{*}{$\delta / \phi$} & \multirow[b]{2}{*}{$K_{\mathrm{h}}$} & \multicolumn{7}{|l|}{$\phi\left(^{\circ}\right)$} \\
\hline & & 15 & 20 & 25 & 30 & 35 & 40 & 45 \\
\hline \multirow[t]{4}{*}{0} & 0 & 1.70 & 2.04 & 2.46 & 3.00 & 3.69 & 4.60 & 5.83 \\
\hline & 0.10 & 1.56 & 1.89 & 2.30 & 2.82 & 3.49 & 4.38 & 5.58 \\
\hline & 0.15 & 1.47 & 1.80 & 2.21 & 2.73 & 3.39 & 4.27 & 5.46 \\
\hline & 0.20 & 1.37 & 1.71 & 2.12 & 2.63 & 3.29 & 4.15 & 5.33 \\
\hline \multirow[t]{5}{*}{$1 / 3$} & 0 & 1.89 & 2.39 & 3.08 & 4.05 & 5.48 & 7.70 & 11.35 \\
\hline & 0.05 & 1.81 & 2.30 & 2.97 & 3.91 & 5.31 & 7.48 & 11.07 \\
\hline & 0.10 & 1.71 & 2.19 & 2.84 & 3.77 & 5.14 & 7.27 & 10.78 \\
\hline & 0.15 & 1.60 & 2.08 & 2.72 & 3.62 & 4.96 & 7.04 & 10.49 \\
\hline & 0.20 & 1.47 & 1.95 & 2.58 & 3.47 & 4.78 & 6.81 & 10.19 \\
\hline \multirow{6}{*}{$1 / 2$} & 0.05 & 1.89 & 2.47 & 3.29 & 4.53 & 6.46 & 9.70 & 15.57 \\
\hline & 0.10 & 1.79 & 2.35 & 3.15 & 4.35 & 6.24 & 9.40 & 15.15 \\
\hline & 0.15 & 1.67 & 2.22 & 3.01 & 4.18 & 6.01 & 9.10 & 14.73 \\
\hline & 0.20 & 1.53 & 2.08 & 2.85 & 3.99 & 5.78 & 8.79 & 14.29 \\
\hline & 0.25 & 1.32 & 1.92 & 2.68 & 3.79 & 5.54 & 8.48 & 13.85 \\
\hline & 0.30 & - & 1.73 & 2.50 & 3.59 & 5.29 & 8.15 & 13.40 \\
\hline \multirow[t]{5}{*}{$2 / 3$} & 0 & 2.08 & 2.77 & 3.79 & 5.40 & 8.06 & 12.83 & 22.22 \\
\hline & 0.05 & 1.98 & 2.65 & 3.64 & 5.20 & 7.80 & 12.46 & 21.65 \\
\hline & 0.10 & 1.87 & 2.52 & 3.48 & 5.00 & 7.53 & 12.08 & 21.06 \\
\hline & 0.15 & 1.74 & 2.37 & 3.32 & 4.79 & 7.25 & 11.68 & 20.47 \\
\hline & 0.20 & 1.58 & 2.22 & 3.14 & 4.57 & 6.96 & 11.28 & 19.86 \\
\hline \multirow{2}{*}{1} & 0.25 & 1.44 & 2.28 & 3.47 & 5.49 & 9.17 & 16.60 & 33.43 \\
\hline & 0.30 & - & 2.03 & 3.22 & 5.17 & 8.74 & 15.94 & 32.33 \\
\hline
\end{tabular}


Table 4. Seismic passive earth pressure coefficient $K_{\mathrm{pqE}}(\beta / \phi=\lambda / \phi=0)$.

\begin{tabular}{|c|c|c|c|c|c|c|c|c|}
\hline \multirow[b]{2}{*}{$\delta / \phi$} & \multirow[b]{2}{*}{$\mathrm{K}_{\mathrm{h}}$} & \multicolumn{7}{|l|}{$\phi\left(^{\circ}\right)$} \\
\hline & & 15 & 20 & 25 & 30 & 35 & 40 & 45 \\
\hline \multirow[t]{4}{*}{0} & 0 & 1.70 & 2.04 & 2.46 & 3.00 & 3.69 & 4.60 & 5.83 \\
\hline & 0.10 & 1.56 & 1.89 & 2.30 & 2.82 & 3.49 & 4.38 & 5.58 \\
\hline & 0.15 & 1.47 & 1.80 & 2.21 & 2.73 & 3.39 & 4.27 & 5.46 \\
\hline & 0.20 & 1.37 & 1.71 & 2.12 & 2.63 & 3.29 & 4.15 & 5.33 \\
\hline \multirow[t]{5}{*}{$1 / 3$} & 0 & 1.88 & 2.37 & 3.03 & 3.95 & 5.28 & 7.29 & 10.49 \\
\hline & 0.05 & 1.80 & 2.28 & 2.93 & 3.83 & 5.14 & 7.11 & 10.27 \\
\hline & 0.10 & 1.71 & 2.18 & 2.82 & 3.71 & 4.99 & 6.93 & 10.04 \\
\hline & 0.15 & 1.60 & 2.07 & 2.70 & 3.57 & 4.84 & 6.75 & 9.81 \\
\hline & 0.20 & 1.47 & 1.95 & 2.57 & 3.43 & 4.67 & 6.55 & 9.56 \\
\hline \multirow{6}{*}{$1 / 2$} & 0.05 & 1.88 & 2.42 & 3.19 & 4.31 & 6.00 & 8.71 & 13.33 \\
\hline & 0.10 & 1.78 & 2.32 & 3.07 & 4.17 & 5.83 & 8.49 & 13.03 \\
\hline & 0.15 & 1.67 & 2.20 & 2.95 & 4.02 & 5.65 & 8.26 & 12.73 \\
\hline & 0.20 & 1.53 & 2.07 & 2.81 & 3.86 & 5.46 & 8.02 & 12.42 \\
\hline & 0.25 & 1.32 & 1.92 & 2.65 & 3.69 & 5.26 & 7.78 & 12.09 \\
\hline & 0.30 & - & 1.73 & 2.48 & 3.51 & 5.05 & 7.52 & 11.76 \\
\hline \multirow[t]{5}{*}{$2 / 3$} & 0 & 2.03 & 2.65 & 3.56 & 4.93 & 7.09 & 10.72 & 17.29 \\
\hline & 0.05 & 1.94 & 2.56 & 3.45 & 4.78 & 6.90 & 10.47 & 16.93 \\
\hline & 0.10 & 1.84 & 2.45 & 3.32 & 4.63 & 6.71 & 10.20 & 16.55 \\
\hline & 0.15 & 1.73 & 2.33 & 3.18 & 4.46 & 6.50 & 9.93 & 16.17 \\
\hline & 0.20 & 1.58 & 2.19 & 3.03 & 4.29 & 6.28 & 9.64 & 15.77 \\
\hline \multirow{3}{*}{1} & 0.20 & 1.66 & 2.37 & 3.40 & 5.05 & 7.85 & 12.97 & 23.29 \\
\hline & 0.25 & 1.43 & 2.19 & 3.22 & 4.83 & 7.56 & 12.57 & 22.69 \\
\hline & 0.30 & - & 1.98 & 3.01 & 4.59 & 7.26 & 12.16 & 22.06 \\
\hline
\end{tabular}

the passive earth pressure coefficients $K_{\mathrm{p} \gamma \mathrm{E}}$ and $K_{\mathrm{pqE}}$ are affected by earthquakes, extensive numerical results based on the present failure mechanism are presented in Tables 3 and 4.

The passive earth pressure coefficients $K_{\mathrm{p} \gamma \mathrm{E}}$ and $K_{\mathrm{pqE}}$ decrease with an increase in $K_{\mathrm{h}}$. The reduction is more significant for looser soils with lower $\phi$ values than for denser soils with higher $\phi$ values. For example, for $\delta / \phi=1$, the reduction of the coefficient $K_{\mathrm{p} \gamma \mathrm{E}}$ is $16 \%$ for $\phi=45^{\circ}$ and $35 \%$ for $\phi=$ $20^{\circ}$ when $K_{\mathrm{h}}$ increases from 0 to 0.3 . Finally, it should be mentioned that the seismic acceleration generated by earthquakes not only imposes extra loading on a soil mass but also shifts the sliding surface to less favorable positions.

Figure 11 shows that the critical slip surface becomes more extended as the acceleration intensity increases.

\subsubsection{Comparison of results with existing solutions}

To see the validity of the present upper-bound solution, the seismic passive earth pressure coefficients are calculated and compared with solutions given by other authors.

Chang and Chen (1982) (cf. Chen and Liu 1990) considered a log-sandwich failure mechanism and gave rigorous upper-bound solutions for the coefficient $K_{\mathrm{p} \gamma \mathrm{E}}$. The upperbound solutions given by the present mechanism and those given by Chen and Liu (1990) are presented in Fig. 12.

As in the static case, the present upper-bound solutions are better than those of Chen and Liu (1990); the improvement attains $18.2 \%$ when $\phi=45^{\circ}, \delta / \phi=1, \beta / \phi=1, \lambda / \phi=0$, and $K_{\mathrm{h}}=0.3$. Therefore, the present failure mechanism gives interesting solutions for the seismic passive earth pressure coefficients for translational wall movement. Further investi- 
Fig. 11. Critical slip surfaces for $\phi=20^{\circ}, \delta / \phi=1, \beta / \phi=\lambda / \phi=$ 0 , and $K_{\mathrm{h}}=0$ and 0.2 .
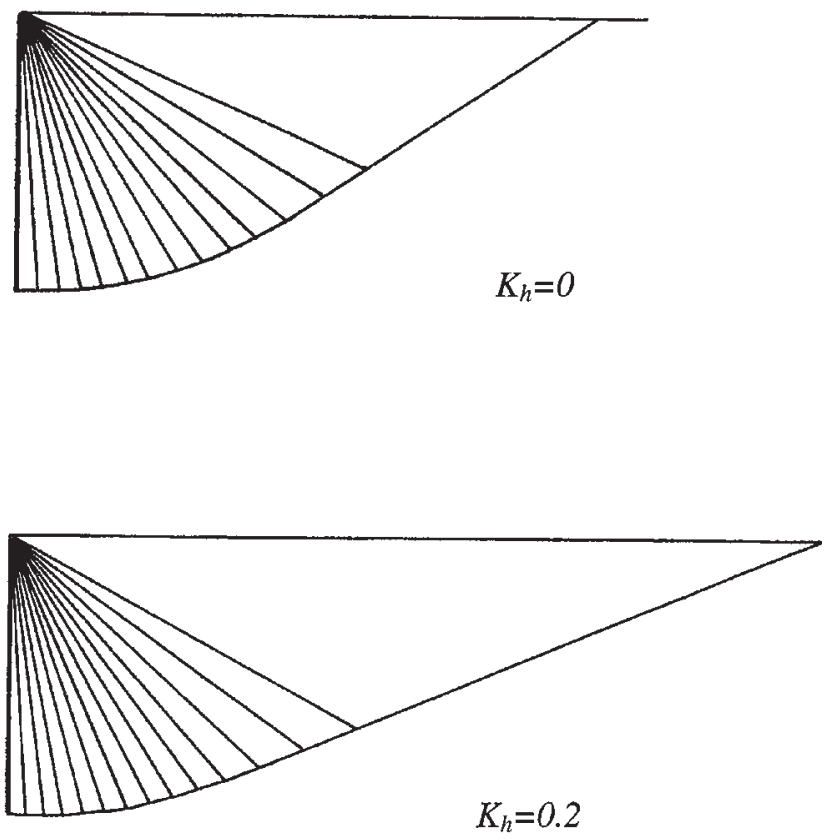

Fig. 12. Comparison of the coefficient $K_{\mathrm{p} \gamma \mathrm{E}}$ from the present solution with that of Chen and Liu (1990) for $\phi=45^{\circ}, \delta / \phi=1$, $\lambda / \phi=0$, and $K_{\mathrm{h}}=0.3$.

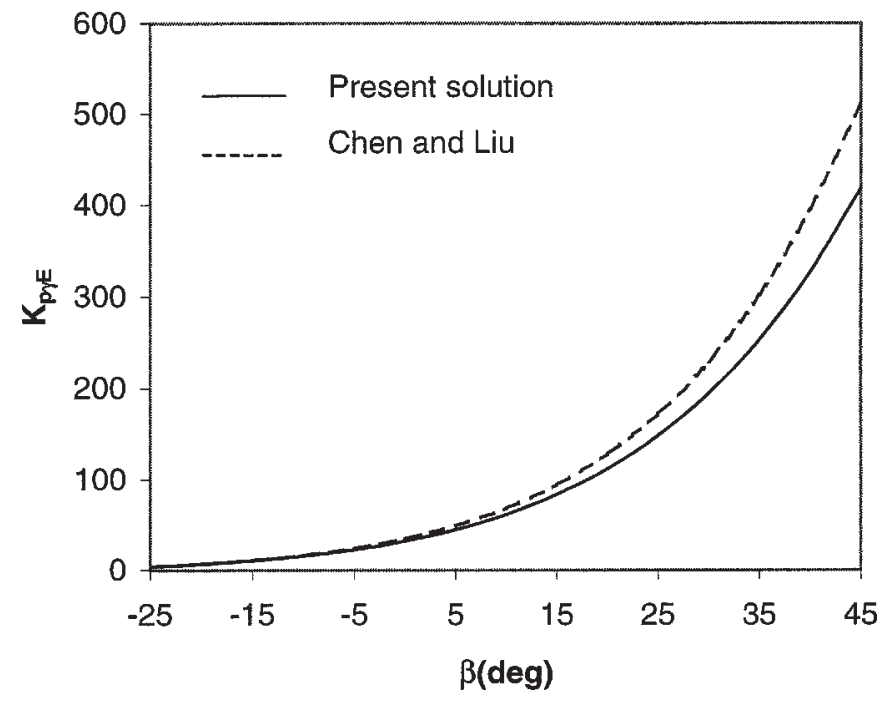

gation remains necessary for the elaboration of adequate rotational failure mechanism.

\section{Conclusions}

A translational, kinematically admissible failure mechanism has been considered for the calculation of the static and seismic passive earth pressures using the upper-bound method of the limit analysis theory. The solutions presented are rigorous upper-bound solutions in the framework of the limit analysis theory. The numerical results obtained lead to the following conclusions.
For the static case, the present results for the coefficient $K_{\mathrm{pq}}$ are almost identical to those given by Kérisel and Absi (1990) using the slip line method and those given by Chen and Liu (1990) using the upper-bound method in limit analysis for a log-sandwich mechanism. For the coefficient $K_{\mathrm{pc}}$, the present analysis has shown that the traditional formula given by the theorem of corresponding states (Caquot and Kérisel 1948) is also valid in the present analysis using the upper-bound method of the limit analysis theory. For the coefficient $K_{\mathrm{p} \gamma}$, the present upper-bound solutions are better than those of Chen and Liu (1990), since one obtains smaller upper-bound solutions; the improvement is $21 \%$ for $\phi=45^{\circ}$, $\delta / \phi=1, \beta / \phi=1$, and $\lambda / \phi=-1 / 3$. On the other hand, the comparison between the present solutions and the currently accepted values of Caquot and Kérisel (1948) has shown that the maximum difference is less than $12.2 \%$ for the practical configurations $\left(\phi \leq 45^{\circ}, 0 \leq \delta / \phi \leq 2 / 3, \lambda / \phi=0, \beta / \phi \leq 1 / 3\right)$.

For the seismic case, the present multiblock failure mechanism continues to give smaller upper-bound solutions for the coefficient $K_{\mathrm{p} \gamma \mathrm{E}}$ than the log-sandwich mechanism; the improvement is $18.2 \%$ for $\phi=45^{\circ}, \delta / \phi=1, \beta / \phi=1, \lambda / \phi=0$, and $K_{\mathrm{h}}=0.3$. Extensive numerical results for the present seismic passive earth pressure coefficients $K_{\mathrm{p} \gamma \mathrm{E}}$ and $K_{\mathrm{pqE}}$ are presented for practical use in geotechnical engineering.

\section{References}

Basudhar, P.K., Valsangkar, A.J., and Madhav, M.R. 1979. Optimal lower bound of passive earth pressure using finite elements and non-linear programming. International Journal for Numerical and Analytical Methods in Geomechanics, 3(4): 367-379.

Bilz, P., Franke, D., and Pietsch, C. 1985. Earth pressure of soils with friction and cohesion. In Proceedings of the 11th International Conference on Soil Mechanics and Foundation Engineering, San Francisco, Vol. 2, pp. 401-405.

Budhu, M., and Al-Karni, A. 1993. Seismic bearing capacity of soils. Géotechnique, 43(4): 181-187.

Caquot, A., and Kérisel, J. 1948. Tables de poussée et de butée. Gauthier-Villars, Paris.

Chang, M.F., and Chen, W.F. 1982. Lateral earth pressures on rigid retaining walls subjected to earthquake forces. In Solid mechanics archives. Vol. 7. Martinus Nijhoff Publishers, The Hague, The Netherlands, pp. 315-362.

Chen, W.F. 1975. Limit analysis and soil plasticity. Elsevier, Amsterdam.

Chen, W.F., and Liu, X.L. 1990. Limit analysis in soil mechanics. Elsevier, Amsterdam.

Chen, W.F., and Rosenfarb, J.L. 1973. Limit analysis solutions of earth pressure problems. Soils and Foundations, 13(4): 45-60.

Collins, I.F. 1969. The upper-bound theorem for rigid/plastic solids to include Coulomb friction. Journal of the Mechanics and Physics of Solids, 17: 323-338.

Collins, I.F. 1973. A note on the interpretation of Coulomb's analysis of the thrust on a rough retaining wall in terms of the limit theorems of plasticity theory. Géotechnique, 24(1): 106-108.

Commission of the European Communities. 1994. Design provisions for earthquake resistance of structures - Part 5: foundations, retaining structures and geotechnical aspects. Eurocode8 (European Prestandard). Commission of the European Communities, Luxembourg.

Costet, J., and Sanglerat, G. 1975. Cours pratique de mécanique des sols, plasticité et calcul des tassements. 2nd ed. Dunod Technique Press, Paris, France. (In French.) 
Drescher, A., and Detournay, E. 1993. Limit load in translational failure mechanisms for associative and non-associative materials. Géotechnique, 43(3): 443-456.

Drucker, D.C., Greenberg, H.J., and Prager, W. 1952. Extended limit design theorems for continuous media. Quarterly of Applied Mathematics, 9: 381-389.

Fang, Y.S., Chen, J.M., and Chen, C.Y. 1997. Earth pressures with sloping backfill. Journal of Geotechnical and Geoenvironmental Engineering, ASCE, 123(3): 250-259.

Graham, J. 1971. Calculation of passive pressure in sand. Canadian Geotechnical Journal, 8(4): 566-579.

Hettiaratchi, R.P., and Reece, A.R. 1975. Boundary wedges in two-dimensional passive soil failure. Géotechnique, 25(2): 197-220.

Ishii, Y., Arai, H., and Tsuchida, H. 1960. Lateral earth pressure in an earthquake. In Proceedings of the 2nd World Conference on Earthquake Engineering, Tokyo, Vol. 1, pp. 211-230.

Janbu, N. 1957. Earth pressure and bearing capacity calculations by generalised procedure of slices. In Proceedings of the 4th International Conference of the International Society of Soil Mechanics and Foundation Engineering, Vol. 2, London. pp. 207-213.

Kérisel, J., and Absi, E. 1990. Tables de poussée et de butée des terres. 3rd ed. Presses de l'École Nationale des Ponts et Chaussées, Paris, France. (In French.)

Kobayashi, Y. 1998. Laboratory experiments with an oblique passive wall and rigid plasticity solutions. Soils and Foundations, 38(1): 121-129.

Lee, I.K., and Herington, J.R. 1972. A theoretical study of the pressures acting on a rigid wall by a sloping earth on rockfill. Géotechnique, 22(1): 1-26.

Lee, J.K., and Moore, P.J. 1968. Stability analysis. Application to slopes, rigid and flexible retaining structures. In Selected topics in soil mechanics. Butterworth and Co. Ltd, London, U.K., pp. 381-465.

L'herminier, R., and Absi, E. 1962. Equilibre limite d'un coin dans un milieu non pesant, tables numériques. Cahiers de la recherche, No. 16. Eyrolles, Paris.

Lysmer, J. 1970. Limit analysis of plane problems in soil mechanics. Journal of the Soil Mechanics and Foundations Division, ASCE, 96(SM4): 1311-1334.

Michalowski, R.L. 1999. Closure on 'Stability of uniformly reinforced slopes'. Journal of Geotechnical and Geoenvironmental Engineering, ASCE, 125(1): 81-86.

Michalowski, R.L., and Shi, L. 1995. Bearing capacity of footings over two-layer foundation soils. Journal of Geotechnical Engineering, ASCE, 121(5): 421-428.

Michalowski, R.L., and Shi, L. 1996. Closure on 'Bearing capacity of footings over two-layer foundation soils'. Journal of Geotechnical Engineering, ASCE, 122(8): 701-703.

Mononobe, N., and Matsuo, H. 1929. On determination of earth pressure during earthquakes. In Proceedings of the World Engineering Congress, Tokyo, Vol. 9, p. 275.

Mroz, Z., and Drescher, A. 1969. Limit plasticity approach to some cases of flow of bulk solids. Journal of Engineering for Industry, 91: $357-364$.

Okabe, S. 1924. General theory on earth pressure and seismic stability of retaining walls and dams. Journal of the Japanese Society of Civil Engineers, 10(6): 1277-1323.

Okamoto, S. 1956. Bearing capacity of sandy soil and lateral earth pressure during earthquakes. In Proceedings of the 1 st World Conference on Earthquake Engineering, Calif., pp. 1-26.

Packshaw, S. 1969. Earth pressure and earth resistance. In A century of soil mechanics. The Institution of Civil Engineers, London, U.K., pp. 409-435.
Paolucci, R., and Pecker, A. 1997. Seismic bearing capacity of shallow strip foundations on dry soils. Soils and Foundations, 37(3): 95-105.

Rahardjo, H., and Fredlund, D.G. 1984. General limit equilibrium method for lateral earth forces. Canadian Geotechnical Journal, 21(1): 166-175.

Richards, R., Elms, D.G., and Budhu, M. 1993. Seismic bearing capacity and settlement of foundations. Journal of Geotechnical Engineering, ASCE, 119(4): 662-674.

Rowe, P.W. 1963. Stress-dilatancy, earth pressures, and slopes. Journal of the Soil Mechanics and Foundations Division, ASCE, 89(SM3): 37-61.

Salençon, J. 1990. An introduction to the yield design theory and its application to soil mechanics. European Journal of Mechanics, Series A: Solids, 9(5): 477-500.

Sarma, S.K., and Iossifelis, I.S. 1990. Seismic bearing capacity factors of shallow strip footings. Géotechnique, 40(2): 265-273.

Shields, D.H., and Tolunay, A.Z. 1972. Passive pressure coefficients for sand by the Terzaghi and Peck method. Canadian Geotechnical Journal, 9(4): 501-503.

Shields, D.H., and Tolunay, A.Z. 1973. Passive pressure coefficients by method of slices. Journal of the Geotechnical Engineering Division, ASCE, 99(SM12): 1043-1053.

Sokolovski, V.V. 1960. Statics of soil media. Butterworth, London, U.K.

Sokolovski, V.V. 1965. Statics of granular media. Pergamon Press, New York.

Soubra, A.-H. 1989. Application de la méthode variationnelle au problème de détermination des pressions passives des terres. Influence des forces d'écoulement. Thèse de Doctorat, INSA, Lyon, France. (In French.)

Soubra, A.-H. 1997. Seismic bearing capacity of shallow strip footings in seismic conditions. Proceedings of the Institution of Civil Engineers, Geotechnical Engineering, 125(4): 230-241.

Soubra, A.-H. 1999. Upper-bound solutions for bearing capacity of foundations. Journal of Geotechnical and Geoenvironmental Engineering, ASCE, 125(1): 59-68.

Soubra, A.-H., Kastner, R., and Benmansour, A. 1998. Étude de la butée des terres en présence d'écoulement. Revue Française de Génie Civil, 2(6): 691-707. (In French.)

Soubra, A.-H., Kastner, R., and Benmansour, A. 1999. Passive earth pressures in the presence of hydraulic gradients. Géotechnique, 49(3): 319-330.

Spencer, E. 1975. Forces on retaining walls using the method of slices. Civil Engineering, 45: 18-23.

Terzaghi, K. 1943. Theoretical soil mechanics. Wiley, New York.

\section{List of symbols}

$c$ cohesion
$c^{*}$ residual cohesion due to nonassociativeness
$d_{i}, l_{i}$ discontinuity lines
$\dot{D} \begin{aligned} & \text { rate of energy dissipation per unit length along velocity } \\ & \text { discontinuity }\end{aligned}$
$f_{1}, f_{2}, \ldots$,
$f_{7}$ nondimensional intermediate functions
$H$ wall height
$K_{\mathrm{h}}$ horizontal seismic coefficient
$K_{\mathrm{p} \gamma \mathrm{E}}$,
$K_{\mathrm{pqE}}$,
$\mathrm{K}_{\mathrm{pcE}}$ seismic passive earth pressure coefficients
$K_{\mathrm{p} \gamma}$,
$K_{\mathrm{pq}}, K_{\mathrm{pc}}$ static passive earth pressure coefficients


$K_{\mathrm{p} \gamma, \mathrm{h}}$ horizontal component of static passive earth pressure coefficient $K_{\mathrm{p} \gamma}$

$K_{\mathrm{pq} 0}$ static passive earth pressure coefficient due to a surcharge loading acting normally to the ground surface

$l$ wall length

$n$ number of rigid blocks in the failure mechanism

$P_{\text {a }}$ adhesive force

$P_{\mathrm{p}}$ static passive force

$P_{\mathrm{pE}}$ seismic passive force

$q$ surcharge loading

$S$ horizontal wall movement

$S_{i}$ area of block $i$

$V$ velocity along velocity discontinuity

$V_{0}$ wall velocity

$V_{0,1}$ relative velocity at the soil-structure interface

$V_{i}$ velocity of block $i$

$V_{i, i+1}$ relative velocity between blocks $i$ and $i+1$

$V_{i+1}$ velocity of block $i+1$

$W_{i}$ weight of block $i$

$\dot{W}_{P_{\mathrm{p}}, P_{\mathrm{a}}}$ rate of work due to forces $P_{\mathrm{p}}$ and $P_{\mathrm{a}}$

$\dot{W}_{P_{\mathrm{pE}}, P_{\mathrm{a}}}$ rate of external work due to forces $P_{\mathrm{pE}}$ and $P_{\mathrm{a}}$

$\dot{W}_{q}$ rate of external work due to surcharge loading and corresponding inertia force

$\dot{W}_{\text {soil }}$ rate of work due to soil weights and the corresponding inertia forces in the multiblock mechanism

$\dot{W}_{\gamma}$ rate of work due to soil weight in the one-block mechanism

$\alpha$ inclination of the Rankine passive earth pressures

$\alpha_{i}, \beta_{i}$ angular parameters of failure mechanism

$\beta$ backfill inclination

$\psi$ dilatancy angle

$\delta$ angle of friction at the soil-wall interface

$\phi$ angle of internal friction of the soil

$\phi^{*}$ residual friction angle due to nonassociativeness

$\gamma$ unit weight of the soil

$\lambda$ angle between the soil-wall interface and the vertical direction

$\theta$ inclination of the Rankine slip surface with the horizontal direction

$\omega_{\beta}$ intermediate angular parameter

\section{Appendix 1}

In the case of a vertical rough wall, Drescher and Detournay (1993) and more recently Michalowski (1999) have indicated that two different ways of incorporating the wall friction in the energy-balance equation can be found in the literature (cf. Chen 1975; Mroz and Drescher 1969; Collins 1969,1973 ), and that both approaches lead to an identical force $P_{\mathrm{p}}$. The aim of this appendix is to present and discuss the two approaches in the general case of an inclined rough wall. A third approach is also presented and discussed. The following three approaches consider the simple case of a single rigid block (Fig. A1) ; however, the results remain valid for a multiblock mechanism.

\section{First approach (Chen 1975)}

In the approach of Chen (1975), the velocity jump vector is assumed to be tangential to the wall (Fig. A2). The wall moves horizontally with velocity $V_{0}$ and the wedge moves
Fig. A1. One block failure mechanism.

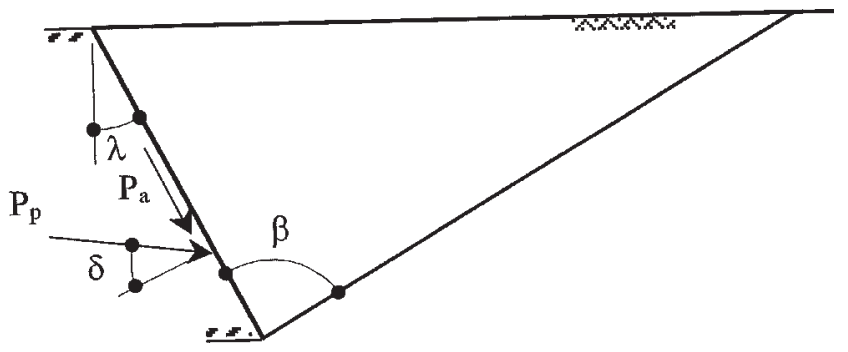

with velocity $V_{1}$. Thus, sliding on the wall surface occurs with sliding vector magnitude $V_{0,1}=V_{1} \cos (\beta-\lambda-\phi) / \cos \lambda$ (see velocity hodograph), and the rate of work dissipation associated with this sliding is

$$
\begin{aligned}
& \dot{D}_{1}=\left(P_{\mathrm{p}} \sin \delta+P_{\mathrm{a}}\right) V_{0,1} \\
&\left(P_{\mathrm{p}} \sin \delta+P_{\mathrm{a}}\right) \frac{\cos (\beta-\lambda-\phi)}{\cos \lambda} V_{1}
\end{aligned}
$$

The energy dissipation rate along the failure surface is given by

$$
\text { [A2] } \quad \dot{D}_{2}=c\left(V_{1} \cos \phi\right) \frac{l \cos \lambda}{\cos (\beta-\lambda)}
$$

The work rates of forces $P_{\mathrm{p}}$ and $P_{\mathrm{a}}$ and the soil weight are

$$
\begin{aligned}
\dot{W}_{P_{\mathrm{p}}, P_{\mathrm{a}}}=\left[P_{\mathrm{p}} \cos (\delta-\lambda)+P_{\mathrm{a}} \sin \lambda\right] V_{0}= \\
{\left[P_{\mathrm{p}} \cos (\delta-\lambda)+P_{\mathrm{a}} \sin \lambda\right] \frac{\sin (\beta-\phi)}{\cos \lambda} V_{1} }
\end{aligned}
$$

and

[A4]

$$
\dot{W}_{\gamma}=-\frac{\gamma l^{2}}{2} \frac{\cos \lambda \sin \beta \cos (\beta-\phi-\lambda)}{\cos (\beta-\lambda)} V_{1}
$$

By equating the rate of external work (eqs. [A3] and [A4]) to the rate of internal energy dissipation (eqs. [A1] and [A2]), one obtains

$$
\begin{array}{r}
P_{\mathrm{p}}\left[\cos (\delta-\lambda) \frac{\sin (\beta-\phi)}{\cos \lambda}-\sin \delta \frac{\cos (\beta-\lambda-\phi)}{\cos \lambda}\right]= \\
\frac{\gamma l^{2}}{2} \frac{\cos \lambda \sin \beta \cos (\beta-\phi-\lambda)}{\cos (\beta-\lambda)}+c l \frac{\cos \lambda \cos \phi}{\cos (\beta-\lambda)} \\
+P_{\mathrm{a}}\left[\frac{\cos (\beta-\lambda-\phi)}{\cos \lambda}-\sin \lambda \frac{\sin (\beta-\phi)}{\cos \lambda}\right]
\end{array}
$$

\section{Second approach (Mroz and Drescher 1969; Collins 1969, 1973)}

In this approach, the inclination of the velocity jump $V_{0,1}$ across the wall is taken as $\delta$ (Fig. A3). The wall moves horizontally with velocity $V_{0}$ and the wedge moves with velocity $V_{1}$ (see velocity hodograph).

The rate of work dissipation along the wall is given by

$$
\dot{D}_{3}=P_{\mathrm{a}} V_{0,1} \cos \delta=P_{\mathrm{a}} \cos \delta \frac{\cos (\beta-\lambda-\phi)}{\cos (\lambda-\delta)} V_{1}
$$


Fig. A2. Velocity field according to Chen (1975).
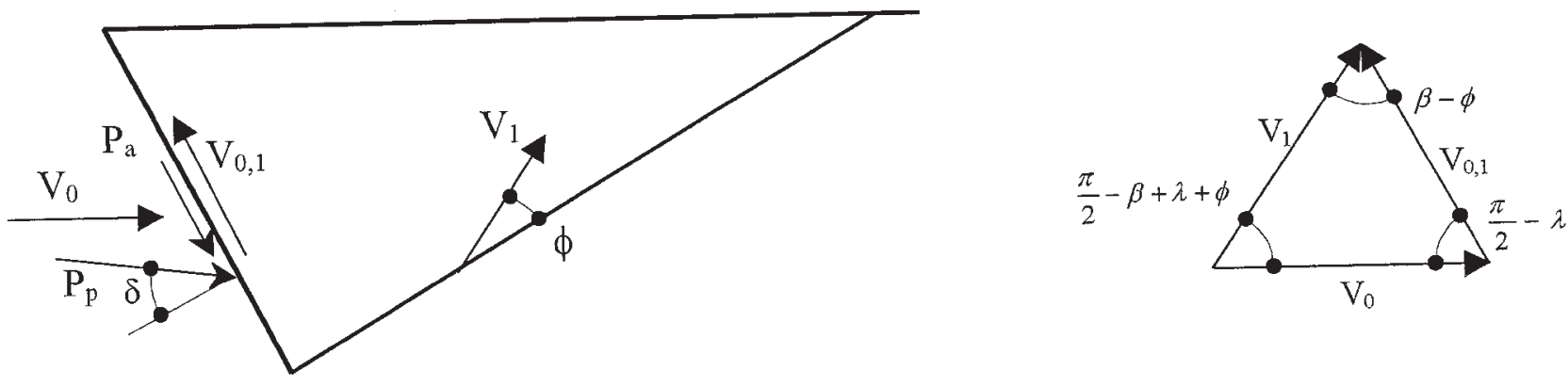

Fig. A3. Velocity field according to Mroz and Drescher (1969) and Collins (1969, 1973).
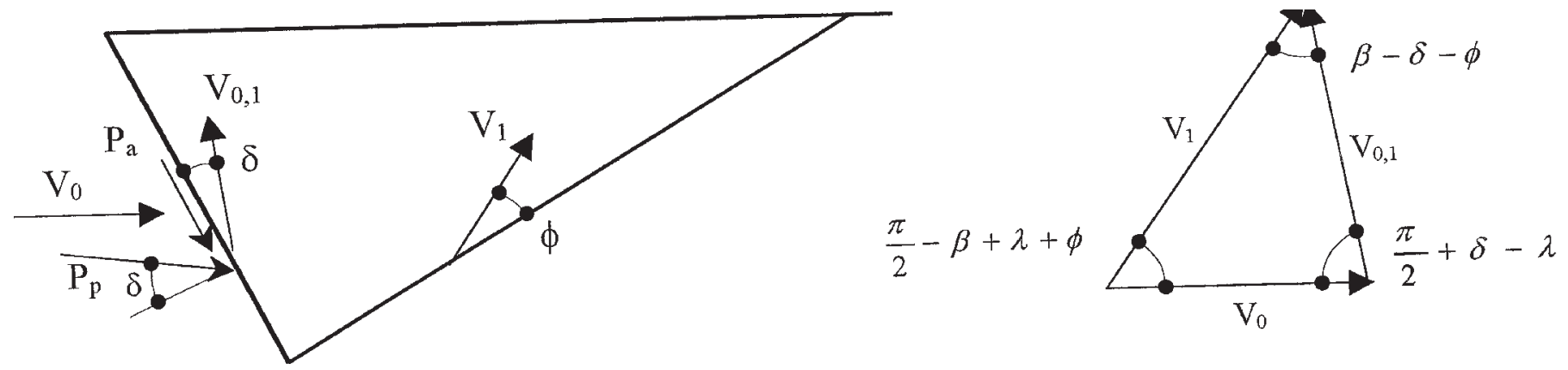

Note that the rate of work dissipation of $P_{\mathrm{p}}$ is equal to zero. On the other hand, the rate of energy dissipation along the failure surface is given by eq. [A2].

The work rate of forces $P_{\mathrm{p}}$ and $P_{\mathrm{a}}$ is

$$
\begin{aligned}
\dot{W}_{P_{\mathrm{p}}, P_{\mathrm{a}}}= & {\left[P_{\mathrm{p}} \cos (\delta-\lambda)+P_{\mathrm{a}} \sin \lambda\right] V_{0}=} \\
& {\left[\left[P_{\mathrm{p}} \cos (\delta-\lambda)+P_{\mathrm{a}} \sin \lambda\right] \frac{\sin (\beta-\phi-\delta)}{\cos (\lambda-\delta)}\right] V_{1} }
\end{aligned}
$$

The work rate of soil weight is given by eq. [A4]. By equating the rate of external work (eqs. [A4] and [A7]) to the rate of internal energy dissipation (eqs. [A2] and [A6]), one obtains

$$
\begin{aligned}
& P_{\mathrm{p}}[\sin (\beta-\phi-\delta)]=\frac{\gamma l^{2}}{2} \frac{\cos \lambda \sin \beta \cos (\beta-\phi-\lambda)}{\cos (\beta-\lambda)} \\
& +c l \frac{\cos \lambda \cos \phi}{\cos (\beta-\lambda)} \\
& +P_{\mathrm{a}}\left[\cos \delta \frac{\cos (\beta-\lambda-\phi)}{\cos (\lambda-\delta)}-\sin \lambda \frac{\sin (\beta-\delta-\phi)}{\cos (\lambda-\delta)}\right]
\end{aligned}
$$

Third approach (present analysis)

In this approach, the passive force $P_{\mathrm{p}}$ and the adhesive force $P_{\mathrm{a}}$ are considered as two external forces acting on the soil wedge which moves with velocity $V_{1}$ (Fig. A4).

The rate of work dissipation along the failure surface is given by eq. [A2]. The work rates of forces $P_{\mathrm{p}}$ and $P_{\mathrm{a}}$ are

$$
\dot{W}_{P_{\mathrm{p}}}=P_{\mathrm{p}} \cos \left(\frac{\pi}{2}+\delta-\beta+\phi\right) V_{1}
$$

and
Fig. A4. Velocity field according to the present analysis.

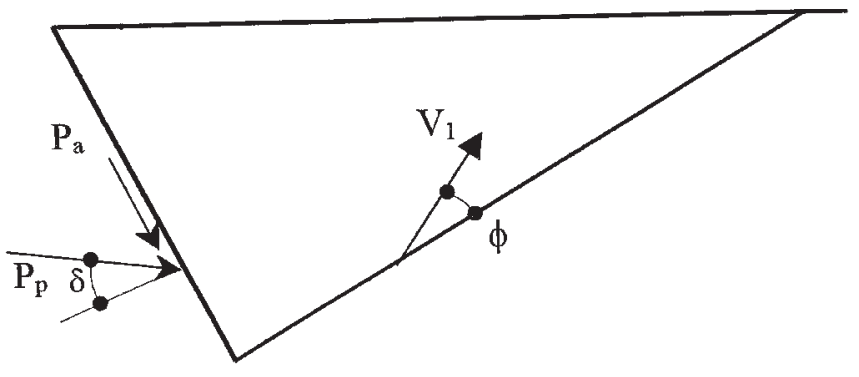

[A10] $\dot{W}_{P_{\mathrm{a}}}=P_{\mathrm{a}} \cos (\beta-\phi) V_{1}$

The work rate of soil weight is given by eq. [A4]. By equating the rate of external work (eqs. [A4], [A9], and [A10]) to the rate of internal energy dissipation (eq. [A2]), one obtains

$$
\text { [A11] } \begin{aligned}
P_{\mathrm{p}}[\sin (\beta-\phi-\delta)] & =\frac{\gamma l^{2}}{2} \frac{\cos \lambda \sin \beta \cos (\beta-\phi-\lambda)}{\cos (\beta-\lambda)} \\
& +c l \frac{\cos \lambda \cos \phi}{\cos (\beta-\lambda)}+P_{\mathrm{a}}[\cos (\beta-\phi)]
\end{aligned}
$$

\section{Discussion}

By simple trigonometric manipulations or by numerical calculations one can easily see that the three approaches lead strictly to the same result of $P_{\mathrm{p}}$. Hence, in the present paper the third approach is adopted in which the passive and adhesive forces are considered external forces acting on the soil wedge which moves with velocity $V_{1}$. In this analysis, no indication is made with regard to the soil-wall velocity $V_{0,1}$. This confirms the conclusion of Drescher and Detournay 
(1993) and Michalowski (1999) that the hypothesis of associativeness or nonassociativeness along the soil-structure interface has no influence on the limit load.

\section{Appendix 2}

This appendix presents the rate of external work and the rate of internal energy dissipation along the different velocity discontinuities.

\section{Geometry}

For the triangular block $i$, the lengths $l_{i}$ and $d_{i}$ and the surface $S_{i}$ are given as follows:

$$
l_{i}=l \prod_{j=1}^{i} \frac{\sin \beta_{j}}{\sin \left(\alpha_{j}+\beta_{j}\right)}
$$

$$
\begin{aligned}
& d_{i}=l \frac{\sin \alpha_{i}}{\sin \beta_{i}} \prod_{j=1}^{i} \frac{\sin \beta_{j}}{\sin \left(\alpha_{j}+\beta_{j}\right)} \\
& S_{i}=\frac{l^{2}}{2} \frac{\sin \alpha_{i} \sin \left(\alpha_{i}+\beta_{i}\right)}{\sin \beta_{i}} \prod_{j=1}^{i} \frac{\sin ^{2} \beta_{j}}{\sin ^{2}\left(\alpha_{j}+\beta_{j}\right)}
\end{aligned}
$$

\section{Velocities}

From the velocity hodographs (cf. Fig. $2 b$ ), the blocks and interblocks velocities are given as follows:

$$
\begin{aligned}
& V_{i}=\prod_{j=1}^{i-1} \frac{\sin \left(\alpha_{j}+\beta_{j}-2 \phi\right)}{\sin \left(\beta_{j+i}-2 \phi\right)} V_{1} \\
& V_{i, i+1}=\frac{\sin \left(\beta_{i}-\beta_{i+1}+\alpha_{i}\right)}{\sin \left(\beta_{i+1}-2 \phi\right)} \prod_{j=1}^{i-1} \frac{\sin \left(\alpha_{j}+\beta_{j}-2 \phi\right)}{\sin \left(\beta_{j+1}-2 \phi\right)} V_{1}
\end{aligned}
$$

\section{Rate of external work}

The rate of external work for the failure mechanism can be calculated as follows:

(1) Rate of external work due to self-weights and inertia forces of the $n$ triangular rigid blocks: The rate of external work due to self-weight in a rigid block is the vertical component of the velocity in that block multiplied by the weight of the block. The rate of external work due to the seismic force in a block can be obtained by the multiplication of the horizontal inertia force of that block and the corresponding horizontal velocity. By summing this rate of external work due to self-weights and inertia forces over the $n$ triangular blocks, one obtains

$$
\dot{W}_{\text {soil }}=\frac{\gamma l^{2}}{2}\left[f_{1}\left(\alpha_{i}, \beta_{i}\right)+K_{\mathrm{h}} f_{2}\left(\alpha_{i}, \beta_{i}\right)\right] V_{1}
$$

where
[B7]

$$
\begin{aligned}
f_{1}= & \\
& -\sum_{i=1}^{n}\left[\frac{\sin \alpha_{i} \sin \left(\alpha_{i}+\beta_{i}\right)}{\sin \beta_{i}} \cos \left(\beta_{i}-\phi-\sum_{j=1}^{i-1} \alpha_{j}-\lambda\right)\right. \\
& \left.\times \prod_{j=1}^{i} \frac{\sin ^{2} \beta_{j}}{\sin ^{2}\left(\alpha_{j}+\beta_{j}\right)} \prod_{j=1}^{i-1} \frac{\sin \left(\alpha_{j}+\beta_{j}-2 \phi\right)}{\sin \left(\beta_{j+1}-2 \phi\right)}\right]
\end{aligned}
$$

[B8] $f_{2}=$

$$
\begin{array}{r}
\sum_{i=1}^{n}\left[\frac{\sin \alpha_{i} \sin \left(\alpha_{i}+\beta_{i}\right)}{\sin \beta_{i}} \sin \left(\beta_{i}-\phi-\sum_{j=1}^{i-1} \alpha_{j}-\lambda\right)\right. \\
\left.\times \quad \prod_{j=1}^{i} \frac{\sin ^{2} \beta_{j}}{\sin ^{2}\left(\alpha_{j}+\beta_{j}\right)} \prod_{j=1}^{i-1} \frac{\sin \left(\alpha_{j}+\beta_{j}-2 \phi\right)}{\sin \left(\beta_{j+1}-2 \phi\right)}\right]
\end{array}
$$

(2) Rate of external work due to the passive force $P_{\mathrm{pE}}$ and the adhesive force $P_{\mathrm{a}}$ : The rate of external work due to these forces is given as

$$
\begin{aligned}
\dot{W}_{P_{\mathrm{pE}}, P_{\mathrm{a}}}= & \\
& {\left[P_{\mathrm{pE}} \cos \left(\frac{\pi}{2}-\beta_{1}+\phi+\delta\right)-P_{\mathrm{a}} \cos \left(\beta_{1}-\phi\right)\right] V_{1} }
\end{aligned}
$$

where

[B10] $P_{\mathrm{a}}=c \frac{\tan \delta}{\tan \phi} l$

(3) Rate of external work due to the surcharge loading and the corresponding inertia force: This rate of external work is given as

[B 11] $\dot{W}_{\mathrm{q}}=q l\left[f_{3}\left(\alpha_{i}, \beta_{i}\right)+K_{\mathrm{h}} f_{4}\left(\alpha_{i}, \beta_{i}\right)\right] V_{1}$

where

$$
\begin{aligned}
& f_{3}=-\cos \left(\beta_{n}-\phi-\sum_{j=1}^{n-1} \alpha_{j}-\lambda\right) \\
& \times \prod_{j=1}^{n} \frac{\sin \beta_{j}}{\sin \left(\alpha_{j}+\beta_{j}\right)} \prod_{j=1}^{n-1} \frac{\sin \left(\alpha_{j}+\beta_{j}-2 \phi\right)}{\sin \left(\beta_{j+1}-2 \phi\right)} \\
& \text { [B13] } f_{4}=\sin \left(\beta_{n}-\phi-\sum_{j=1}^{n-1} \alpha_{j}-\lambda\right) \\
& \times \prod_{j=1}^{n} \frac{\sin \beta_{j}}{\sin \left(\alpha_{j}+\beta_{j}\right)} \prod_{j=1}^{n-1} \frac{\sin \left(\alpha_{j}+\beta_{j}-2 \phi\right)}{\sin \left(\beta_{j+1}-2 \phi\right)}
\end{aligned}
$$

The total rate of external work is the summation of these three contributions, that is, eqs. [B6], [B9], and [B11]:

[B 14] $\sum \dot{W}_{\text {ext }}=\dot{W}_{\text {soil }}+\dot{W}_{P_{\mathrm{pE}}, P_{\mathrm{a}}}+\dot{W}_{\mathrm{q}}$

Rate of internal energy dissipation

(1) Along lines $d_{i}(i=1, \ldots, n)$

[B15] $\quad \dot{D}_{d_{i}(i=1, . ., n)}=c l f_{5}\left(\alpha_{i}, \beta_{i}\right) V_{1}$ 
where

[B16] $f_{5}=\cos \phi \sum_{i=1}^{n}\left[\frac{\sin \alpha_{i}}{\sin \beta_{i}}\right.$

$$
\left.\times \prod_{j=1}^{i} \frac{\sin \beta_{j}}{\sin \left(\alpha_{j}+\beta_{j}\right)} \prod_{j=1}^{i-1} \frac{\sin \left(\alpha_{j}+\beta_{j}-2 \phi\right)}{\sin \left(\beta_{j+1}-2 \phi\right)}\right]
$$

(2) Along the radial lines $l_{i}(i=1, \ldots, n-1)$

[B17] $\dot{D}_{l_{i}(i=1, . ., n-1)}=c l f_{6}\left(\alpha_{i}, \beta_{i}\right) V_{1}$

where

[B18] $f_{6}=\cos \phi \sum_{i=1}^{n-1}\left[\frac{\sin \left(\beta_{i}-\beta_{i+1}+\alpha_{i}\right)}{\sin \left(\beta_{i+1}-2 \phi\right)}\right.$

$\left.\times \prod_{j=1}^{i} \frac{\sin \beta_{j}}{\sin \left(\alpha_{j}+\beta_{j}\right)} \prod_{j=1}^{i-1} \frac{\sin \left(\alpha_{j}+\beta_{j}-2 \phi\right)}{\sin \left(\beta_{j+1}-2 \phi\right)}\right]$
The total rate of energy dissipation is the summation of these two parts, that is, eqs. [B15] and [B17]:

[B19] $\sum \dot{D}=\dot{D}_{d_{i}(i=1, . ., n)}+\dot{D}_{l_{i}(i=1, . ., n-1)}$

By equating $\sum \dot{W}_{\text {ext }}$ in eq. [B14] to $\sum \dot{D}$ in eq. [B19], we have

[B20] $K_{\mathrm{p} \gamma \mathrm{E}}=-\frac{f_{1}+K_{\mathrm{h}} f_{2}}{\sin \left(\beta_{1}-\phi-\delta\right)}$

[B21] $K_{\mathrm{pqE}}=-\frac{f_{3}+K_{\mathrm{h}} f_{4}}{\sin \left(\beta_{1}-\phi-\delta\right)}$

and

[B22] $K_{\mathrm{pcE}}=\frac{f_{5}+f_{6}+f_{7}}{\sin \left(\beta_{1}-\phi-\delta\right)}$

where

[B23] $f_{7}=\frac{\tan \delta}{\tan \phi} \cos \left(\beta_{1}-\phi\right)$ 